\title{
Intracellular Adaptation of Brucella abortus
}

\author{
Julie Lamontagne ${ }^{\dagger}$, Anik Forest $^{\dagger}$, Elena Marazzo ${ }^{\dagger}$, François Denis ${ }^{\dagger}$, Heather Butler ${ }^{\dagger}$, Jean- \\ François Michaud ${ }^{\dagger}$, Lyne Boucher ${ }^{\dagger}$, Ida Pedro ${ }^{\dagger}$, Annie Villeneuve ${ }^{\dagger}$, Dmitri Sitnikov ${ }^{\dagger}$, Karine \\ Trude $^{\dagger}$, Najib Nassif ${ }^{\dagger}$, Djamila Boudjelti ${ }^{\dagger}$, Fadi Tomaki ${ }^{\dagger}$, Esteban Chaves-Olarte $\ddagger, \S$, Caterina \\ Guzmán-Verri ${ }^{\ddagger}$, Sylvain Brunet ${ }^{\dagger}$, Alexandra Côté-Martin ${ }^{\dagger}$, Joanna Hunter ${ }^{\dagger}$, Edgardo \\ Moreno $\neq$, and Eustache Paramithiotis ${ }^{\dagger},{ }^{*}$ \\ † Caprion Proteomics Inc. 7150 Alexander-Fleming, Montreal, Quebec, Canada, H4S 2C8 \\ ‡ Programa de Investigación en Enfermedades Tropicales, Escuela de Medicina Veterinaria, \\ Universidad Nacional, Heredia, Costa Rica \\ $\S$ Centro de Investigación en Enfermedades Tropicales, Facultad de Microbiología, Universidad de \\ Costa Rica, San José, Costa Rica
}

\begin{abstract}
Macrophages were infected with virulent B. abortus strain 2308 or attenuated strain 19. Intracellular bacteria were recovered at different times after infection and their proteomes compared. The virulent strain initially reduced most biosynthesis and altered its respiration, adaptations reversed later in infection. The attenuated strain was unable to match the magnitude of the virulent strain's adjustments. The results provide insight into mechanisms utilized by Brucella to establish intracellular infections.
\end{abstract}

\section{Keywords}

Brucella abortus; virulence; timecourse; proteomics; intracellular infection

\section{Introduction}

The genus Brucella is composed of pathogenic intracellular bacteria that infect phagocytic and epithelial cells of domestic and wild mammals, as well as humans ${ }^{1}$. Brucella species were originally characterized as facultative intracellular pathogens but, given their physiology and phylogenetic relationship with other alpha-proteobacteria, it appears their primary niche is the intracellular environment. Therefore, it may be more appropriate to designate them as facultative extracellular intracellular pathogens ${ }^{2,3}$.

Members of the genus Brucella do not display classical virulence factors such as exotoxins, capsules, resistant forms, toxic LPS, fimbria, flagella, plasmids or type III secretion systems.

\footnotetext{
Corresponding Author Footnote: To whom correspondence should be addressed: Eustache Paramithiotis; Tel: (514) 228-3627; Fax: (514) 940-3620; E-mail: eparamithiotis@caprion.com.

jlamontagne@caprion.com, aforest@caprion.com,emarazzo@caprion.com,fdenis@caprion.com, hbutler@caprion.com, jmichaud@caprion.com, lboucher@caprion.com, ipedro@caprion.com, avilleuneuve@caprion.com,dsitnikov@caprion.com, ktrudel@caprion.com,nnassif@caprion.com,dboudjelti@caprion.com,ftomaki@caprion.com, echaves@medvet.una.ac.cr, catguz@medvet.una.ac.cr, sbrunet@caprion.com,amartin@caprion.com,jhunter@caprion.com,emoreno@medvet.una.ac.cr

Supporting Information Available: Supplemental Tables 1 and 2 list the sequence of all peptides identified per differentially expressed protein, and include median peptide intensities and standard deviations in each of the four time points in Brucella abortus 2308 and S19, respectively. Supplemental Figure 1 shows the MRM verification of proteomics results for 15 proteins. These materials are available free of charge via the Internet at http://pubs.acs.org.
} 
Their non-canonical pathogen-associated molecular patterns are poor activators of the innate immune system ${ }^{4}$. The mechanisms used by Brucella to cause disease are thus not well understood. It is very likely that Brucella bacteria do not depend on single discrete virulence factors for their pathogenicity. Rather, Brucella virulence may be an integrated aspect of its overall physiology in concordance with specific molecular mediators. Indeed, we have previously demonstrated that Brucella is capable of a broad, reversible remodeling of its cell envelope protein composition ${ }^{5}$. The pathogen may therefore be able to extensively adapt its physiology in response to the distinct microenvironments encountered during its intracellular lifecycle. Such metabolic flexibility may be necessary as the host cell microenvironments Brucella encounters are heterogeneous ${ }^{6-8}$.

To investigate the physiological adaptations carried out by Brucella during its intracellular lifecycle, we infected murine macrophages with virulent $B$. abortus 2308 or attenuated $B$. abortus $\mathrm{S} 19^{9}$. At different timepoints after infection we retrieved live intracellular bacteria and compared the changes to both strains' proteomes. After macrophage infection, virulent Brucella is initially found within vacuoles that intersect the early endocytic pathway ${ }^{10,11}$. Following a brief residence in this compartment, virulent Brucella is found within a transitional compartment that maintains sustained interactions with the endoplasmic reticulum (ER). Virulent Brucella appears to survive within this transitional vacuole for a few hours. At this point either the pathogen successfully fuses with ER cysternae and is able to survive and multiply, or it fails and is destroyed inside host phagolysosomes ${ }^{11,12}$. Replication within the ER of ex vivo mouse macrophages typically proceeds for 48-72 hours, with the number of intracellular bacteria steadily declining subsequently ${ }^{13}$.

Attenuated B. abortus S19 appears to be less effective at successfully infecting macrophages. On average fewer S19 bacteria appear to penetrate per macrophage, and proportionally more of those that successfully enter macrophages appear to be destroyed within lysosomes compared virulent $B$. abortus 9,13,14. However, a small number of attenuated S19 bacteria appear able to evade phagolysosomal destruction and replicate inside macrophages ${ }^{14}$. These survivors appear to display a similar intracellular distribution appearance as virulent bacteria ${ }^{15}$. For example, in NF-IL-6 knock-out macrophages the replication of S19 occurs in the perinuclear region compartments devoid of cathepsin $\mathrm{D}$, similar to that for the pathogenic strain 2308 in wild type macrophages ${ }^{13}$. Moreover, the ability of attenuated B. abortus S19 to generate an efficient vaccine protection in cattle appears related to its capacity to achieve a limited replication in macrophages ${ }^{16}$.

We observed that early in infection the virulent strain seemed to reduce carbohydrate based carbon utilization and protein synthesis processes while switching to alternative energy sources and low oxygen tension respiration type. The virulent strain also appeared to prepare early in infection for the replication that normally occurs afterwards. Later in infection the virulent strain significantly increased the expression of proteins associated with key metabolic processes, protein synthesis, iron acquisition, and transport, to pre-infection levels or beyond. The virulent strain also seemed to actively modify its cell envelope. In contrast, the attenuated strain appeared to adjust its metabolic profile to a lesser extent early in infection. Later in infection the attenuated strain appeared unable to revert to pre-infection protein expression levels for key processes. The differentially expressed proteins identified in this study could provide further insights into the global physiological changes associated with a virulent phenotype. Some of these proteins may become the basis of novel antimicrobial targets. 


\section{Materials and methods}

\section{Brucella strains and macrophage infections}

All experiments involving live $B$. abortus were conducted under Biosafety Level 3 (BSL3) conditions. Strains expressing green fluorescent protein (GFP-B. abortus) were constructed by inserting a plasmid pBBR-2-gfp derived from pBBRIMCS-2 containing a Kan ${ }^{\mathrm{R}}$ cassette ${ }^{17}$ as described ${ }^{11}$. Virulent $B$. abortus 2308 , vaccine S19 and GFP-B. abortus strains were grown at $37^{\circ} \mathrm{C}$ in tryptic soy broth (TSB) to stationary phase, and aliquots were frozen at $-70^{\circ} \mathrm{C}$ in TSB/ $20 \%$ glycerol. The genotypic strain characteristics were confirmed by PCR and the phenotypic outer membrane smoothness by crystal violet staining ${ }^{1}$. For each cell infection, an overnight late $\log$ phase bacterial culture in TSB was prepared from a thawed aliquot, harvested by centrifugation at $3000 \times \mathrm{g}$ for $15 \mathrm{~min}$ at room temperature and resuspended immediately in the appropriate infection medium. Murine RAW264.7 macrophages (ATCC TIB-71) were cultured at $37^{\circ} \mathrm{C}$ with $5 \%$ (vol/vol) $\mathrm{CO}_{2}$ in Dulbecco's modified Eagle's medium supplemented with $1.5 \mathrm{~g} / \mathrm{L}$ sodium bicarbonate, $4.5 \mathrm{~g} / \mathrm{L}$ glucose, L-glutamine and $10 \%$ (vol/vol) heatinactivated fetal bovine serum. Two days before infection, cells were seeded in $100 \mathrm{~mm}$ dishes at a concentration of $4.5 \times 10^{6}$ cells per dish. Cell passages 3 through 13 were used for macrophage infection. Cells were infected at a multiplicity of infection (MOI) of 125 for 2308 and 500 for S19. To synchronize the infection, bacteria and cells were centrifuged together at $300 \times \mathrm{g}$ for $5 \mathrm{~min}$ at $4^{\circ} \mathrm{C}$. Following a pulse incubation of $30 \mathrm{~min}$ at $37^{\circ} \mathrm{C}$ with $5 \%(\mathrm{vol} / \mathrm{vol})$ $\mathrm{CO}_{2}$, cells were washed 3 times with phosphate-buffered saline containing $100 \mu \mathrm{g} / \mathrm{ml}$ of gentamicin to kill extracellular bacteria. Cells were then incubated in culture medium supplemented with $100 \mu \mathrm{g} / \mathrm{ml}$ of gentamicin. At 3, 20 or 44 hours post-infection, cells were washed twice with culture medium, harvested and centrifuged at $300 \times \mathrm{g}$ for $5 \mathrm{~min}$ at $4^{\circ} \mathrm{C}$ and bacteria colony forming units (CFU) counted ${ }^{6}$. Infected cell pellets were stored at $-70^{\circ} \mathrm{C}$ until the intracellular bacteria isolation procedure. The 0 hour time-point was established with overnight late log phase cultured bacteria which were processed for proteomics analyses in same manner as intracellular bacteria obtained from infected cells. Six independent sample isolations were prepared per time point.

\section{Intracellular Brucella isolation and processing for mass spectrometry analysis}

Infected cell pellets were resuspended in $0.3 \mathrm{M}$ sucrose $/ 3 \mathrm{mM}$ imidazole/ $\mathrm{HCl} \mathrm{pH} 7.4$ containing protease inhibitors (Roche, Laval, QC, Canada) at approximately $8 \times 10^{7} \mathrm{cells} / \mathrm{ml}$ and homogenized using a stainless-steel dounce homogenizer (Wheaton Science, Millville, NJ). Nuclei and unbroken cells were removed by low speed centrifugation at $505 \times \mathrm{g}$ for $5 \mathrm{~min}$ at $4^{\circ} \mathrm{C}$ over a $0.8 \mathrm{M}$ sucrose cushion. The post-nuclear supernatant was diluted 5 times in $3 \mathrm{mM}$ imidazole/ $\mathrm{HCl} \mathrm{pH} 7.4$ containing protease inhibitors (osmotic shock buffer) and then immediately centrifuged at $3340 \times \mathrm{g}$ for $15 \mathrm{~min}$ at $4^{\circ} \mathrm{C}$ on top of a three-layer discontinuous sucrose gradient composed of $1.5 \mathrm{M}$ sucrose $/ 3 \mathrm{mM}$ imidazole/ $\mathrm{HCl} \mathrm{pH} 7.4$ (bottom layer, 1 $\mathrm{ml}$ ), $1 \mathrm{M}$ sucrose $/ 3 \mathrm{mM}$ imidazole/ $\mathrm{HCl} \mathrm{pH} 7.4$ containing $0.1 \%$ acid-labile surfactant (ALS; Waters, Milford, MA) (middle layer, $1 \mathrm{ml}$ ) and $0.8 \mathrm{M}$ sucrose $/ 3 \mathrm{mM}$ imidazole/ $\mathrm{HCl} \mathrm{pH} 7.4$ (top layer, $1 \mathrm{ml}$ ) in a SW40Ti tube. Bacteria were recovered in the pellet of the gradient and resuspended in $3 \mathrm{mM}$ imidazole/ $\mathrm{HCl} \mathrm{pH} \mathrm{7.4.} \mathrm{An} \mathrm{aliquot} \mathrm{was} \mathrm{used} \mathrm{to} \mathrm{determine} \mathrm{the} \mathrm{number} \mathrm{of}$ viable bacteria recovered by serial 10 -fold dilutions on chocolate agar plates. The remainder was frozen at $-70^{\circ} \mathrm{C}$.

The frozen intracellular bacterial preparations were disrupted by heating at $95^{\circ} \mathrm{C}$ for $30 \mathrm{~min}$ and each sample's protein content was determined by BCA protein assay (Pierce, Rockford, IL) according to the manufacturer's instructions. Twenty- $\mu \mathrm{g}$ aliquots of protein from each sample were frozen at $-70^{\circ} \mathrm{C}$. Antibodies against host organelle markers were obtained from BD Biosciences (San Jose, CA) (CD45, Bip, GS28, Nucleoporin p62), Upstate Biotechnology (Lake Placid, NY) (Na/K ATPase), Stressgen Bioreagents (Victoria, BC, Canada) (HSP60), 
Neomarkers (Fremont, CA) (Actin). The Brucella antibody was obtained from Hyperomics Farma (Pierrefonds, QC, Canada). Quality control Western blots were carried out on infected macrophages and isolated intracellular bacteria as previously described. Serial dilutions of the isolated intracellular bacterial sample replicates revealed similar quantities of LPS as estimated by Western blotting.

A frozen aliquot from each sample was processed for mass spectrometry analysis. Fifty $\mu \mathrm{L}$ of $50 \mathrm{mM}$ ammonium bicarbonate (Sigma-Aldrich, St. Louis, MO) containing $8 \mathrm{M}$ urea were added to each sample and the sample sonicated for $10 \mathrm{~min}$ in a water bath at ambient temperature. Samples were centrifuged at $2000 \times \mathrm{g}$ for $1 \mathrm{~min}$ and $950 \mu \mathrm{L}$ of a cold $\left(-20^{\circ} \mathrm{C}\right)$ chloroform/methanol solution (2:1 v/v) were added. Samples were vortex mixed and incubated at $-20^{\circ} \mathrm{C}$ for $2 \mathrm{~h}$. Subsequently, $100 \mu \mathrm{L}$ of cold $\left(-20^{\circ} \mathrm{C}\right)$ methanol was added and samples were clarified by centrifugation at $21000 \times \mathrm{g}$ for $10 \mathrm{~min}$ at $4^{\circ} \mathrm{C}$. The supernatants were dried under vacuum for 1 hour at ambient temperature, resuspended in $50 \mu \mathrm{L}$ of $100 \mathrm{mM}$ ammonium bicarbonate containing $8 \mathrm{M}$ urea and $1 \%$ (w/v) of acid-labile surfactant (ALS; Waters, Milford, MA) and sonicated for $10 \mathrm{~min}$. After centrifugation for $20 \mathrm{sec}$ at $2000 \times \mathrm{g}$, samples were incubated for $1 \mathrm{~h}$ at ambient temperature. A volume of $450 \mu \mathrm{L}$ of $100 \mathrm{mM}$ ammonium bicarbonate containing 5\% (v/v) of acetonitrile was added. Lys-C (Wako, Richmond, VA) was added to yield a 1:50 enzyme to protein ratio. The samples were incubated for $3 \mathrm{~h}$ at $37^{\circ} \mathrm{C}$. Trypsin (Promega, Madison, WI) was then added at a 1:50 enzyme to protein ratio and samples were incubated for an additional $16 \mathrm{~h}$. Following proteolysis, TCEP (Pierce, Rockford, IL) was added to a final concentration of $10 \mathrm{mM}$, samples were incubated for $30 \mathrm{~min}$ at ambient temperature and then lyophilized. To cleave the acid labile surfactant, samples were incubated for $30 \mathrm{~min}$ at ambient temperature in $100 \mu \mathrm{L}$ of $1 \mathrm{~N} \mathrm{HCl}$ and $100 \mu \mathrm{L}$ of water were added into each sample with subsequent incubation for another half hour at ambient temperature.

\section{Intracellular Brucella characterization and quantitation}

Macrophages infected with GFP-B. abortus were washed with phosphate-buffered saline and fixed with cold $3 \%$ paraformaldehyde (Merck) for 15 min on ice. The slides were washed, incubated for 10 min with $50 \mathrm{mM}$ phosphate buffered saline- $\mathrm{NH}_{4} \mathrm{Cl}$ followed by incubation for 30 min with an anti-B. abortus rabbit antiserum diluted $1 / 250$ in $10 \%$ horse serum in phosphate-buffered saline, containing $0.1 \%$ saponine. The slides were washed three times with phosphate-buffered saline, $0.2 \%$ Tween- 20 and incubated with a goat anti-rabbit IgGrhodamine conjugate diluted $1 / 1000$ in $10 \%$ horse serum in phosphate-buffered saline. The slides were washed, mounted in Mowiol solution and analyzed by fluorescence microscopy ${ }^{18}$. Counts of green and red intracellular fluorescent bacteria were performed in at least 100 infected cells and expressed as a mean of green-red/red fluorescent bacteria per cell. Counts of green or red fluorescent Brucella was also performed in the isolated bacterial pellets. The integrity of the isolated bacteria was also evaluated by transmission electron microscopy. Macrophage monolayers were infected with B. abortus 2308 and intracellular bacteria recovered as described above. The bacterial pellets were fixed with $2.5 \%$ gluteraldehyde (Mecalab, Montreal, QC, Canada) in $0.1 \mathrm{M}$ sodium cacodylate (Mecalab, Montreal, QC, Canada), $2 \%$ paraformaldehyde (Mecalab, Montreal, QC, Canada) in $0.1 \mathrm{M}$ phosphate buffer (VWR, Mississauga, ON, Canada). Samples were placed in a solution of $1 \% \mathrm{OsO}_{4}$ (Electron Microscopy Sciences, Hatfield, PA) and $1.5 \%$ potassium ferrocyanide (Fisher Scientific, Ottawa, ON, Canada) in water for $1 \mathrm{~h}$ for postfixation, dehydrated in graded concentrations of acetone (Fisher Scientific, Ottawa, ON, Canada) and infiltrated with Epon 812 (Mecalab, Montreal, QC, Canada). Thin sections on 200 mesh copper grids (Electron Microscopy Sciences, Hatfield, PA) were stained with $4 \%$ uranyl acetate (Electron Microscopy Sciences, Hatfield, PA) and Reynold's lead (Electron Microscopy Sciences, Hatfield, PA). Preparations were examined with a Philips Tecnai 12 (FEI, Hillsboro, OR) electron microscope operating at $120 \mathrm{kV}$. 


\section{Liquid Chromatography-Mass Spectrometry (LC-MS)}

Peptide digests were analyzed by liquid chromatography coupled to mass spectrometry (LCMS) as described ${ }^{5}$. Briefly, the peptide concentrations were normalized and the samples were injected onto a reversed-phase column (Jupiter C18, Phenomenex, Torrance, CA) for HPLC separation. Samples were injected sequentially, and replicates of samples to be compared were interleaved during analysis. For LC-MS survey scans, the mass spectra were acquired over 400-1600 Da at a rate of 1 spectrum/second. For MS/MS scans, the mass range was 50-2000 $\mathrm{Da}$, and each spectrum was acquired in $2 \mathrm{~s}$. For LC-MS/MS, the duty cycle was one survey scan followed by one product ion scan (MS/MS). Inclusion MS/MS spectra were acquired for target peptides selected by expression analysis (see below) and contained in inclusion lists. Tolerances for inclusion MS/MS acquisition of target peptides were \pm 1 min retention time and $\pm 0.2 \mathrm{Da}$.

\section{Peptide expression analysis}

Significantly and reproducibly differentially expressed peptides were selected by analysis of peptide intensities. Peptides that were differentially expressed during the timecourse for each strain were identified using a paired $t$-test and were statistically significant with a $p$-value less than 0.05 . The minimum differential threshold (peptide intensity ratio; $\mathrm{d} I$ ) was set at 2 . Permutation tests were applied to determine the false discovery rate ${ }^{19}$ of differentially expressed peptides at this stage. Peptides statistically changing in expression level were targeted for sequencing by LC-MS/MS and were compiled into inclusion lists containing retention time, charge state, and $\mathrm{m} / \mathrm{z}$ for each target peptide. A multidimensional scaling analysis of the differentially expressed peptides was employed to visualize differences between each strain during timecourse infection. Unsupervised sorting of blinded replicates along 3 axes of variance (MDS1 to MDS3) was conducted and calculations were performed using GeneLinker software (Improved Outcomes Software, ON, Canada).

\section{Protein identification}

Protein identification was done by submitting LC-MS/MS spectra to Mascot software (MatrixScience, Boston, MA) for searching against the National Center for Biotechnology Information protein database (NCBI). The parameters used for Mascot search and protein homology clustering were previously detailed ${ }^{5}$. The multidimensional fingerprinting method ${ }^{20}$ was also used. Annotation for each protein was performed using ExPASy Proteomics tools (http://us.expasy.org/tools/\#proteome), Kegg GenomeNet Database Service (http://www.genome.jp/) and literature mining of orthologous genes and proteins. The median peptide intensity was calculated per time point and was normalized to the median intensity of the same peptide at the zero time point for each strain. Median protein intensity at each timepoint was calculated using the normalized median intensity of all peptides belonging to the protein.

\section{Peptide expression verification}

Quantitative verification of differentially expressed peptide intensities was performed by multiple reaction monitoring (MRM) ${ }^{21-24}$ on the 4000 QTRAP (Applied Biosystems, Toronto, Canada) operated with a beta release of Analyst 1.5 which allows scheduled MRM experiments. Q1 and Q3 were operated with unit resolution. The mass spectrometer was coupled to the same HPLC set up as for the QTOF analysis. The three most intense transitions were used for each peptide selected for verification. All transitions were monitored with a duty cycle of $4 \mathrm{~s}$ throughout a detection window of $8 \mathrm{~min}$. Between 63 to 110 transitions were monitored in per run. For the BvrR protein, the differential expression pattern was confirmed by Western blotting as previously described ${ }^{5}$. 


\section{Results}

\section{Isolation of intact intracellular Brucella}

Bacteria assigned as time zero corresponded to B. abortus harvested after 15-18 hours of overnight culture. Bacteria at this stage of growth were just after the middle log phase. Such cultures have been used for cell infections previously ${ }^{4,11,25}$. The infection and replication profiles obtained for $B$. abortus S19 and 2308 corresponded to the profiles observed previously 11,12,26: while 2308 numbers considerably increased at 44 hours after infection, only a modest intracellular replication of S19 was achieved at this time point. The first time point selected for recovery of intracellular bacteria was 3 hours after infection. Destruction of a proportion of the internalized Brucella within phagolysosomes has been observed to occur during the first few hours after infection ${ }^{11,12}$. It is thus likely that the bacterial mechanisms that inhibit this process, and subsequently form the pathogen's replication niche, become activated during the first hours after infection. Thus at 3 hours post infection pathogen proteome changes may reflect critical bacterial adaptations for a successful infection. The second time point selected for recovery of intracellular bacteria was 20 hours after infection. This corresponds to a period just after the initial macrophage bactericidal window. At this time Brucella has achieved some replication and it may thus be a key timepoint to observe changes to the pathogen associated with intracellular replication. The final time point for recovery of intracellular bacteria was at 44 hours post infection, a time near the end of the intracellular infection cycle, when infected macrophages harbor the maximum number of intracellular Brucella ${ }^{11}$.

Infected macrophage cultures were homogenized to isolate the intracellular bacteria.

Macrophage proteins from many cellular compartments were readily detectable in the starting homogenate along with antibody reactivity to Brucella LPS (Figure 1A). The final preparations of intracellular bacteria, however, contained Brucella LPS reactivity that was enriched by at least 2 orders of magnitude over the starting material, while the vast majority of host protein reactivity was removed (Figure 1A). The intracellular bacterial preparations readily produced colonies when incubated on chocolate agar plates (data not shown). This result suggested that a large proportion of the isolated bacteria were viable. To verify that most of the bacteria isolated from infected macrophages were in fact intact, preparations from each timepoint were analyzed by two color immunofluorescence microscopy and by electron microscopy (Figure 1B, C). Viability of the isolated Brucella assessed by double fluorescence microscopy demonstrated that between 91-95\% of the recovered bacteria from either strain were viable. In addition, bacteria from all the intracellular infection time points had similar appearance by electron microscopy as late log phase cultured bacteria. Taken together the fluorescence and electron microscopy evidence indicated that most of the bacteria recovered from infected macrophages were indeed viable.

\section{Distinct proteome changes in B. abortus 2308 and $\mathbf{S 1 9}$ during intracellular infection}

Virulent B. abortus 2308 and the vaccine strain S19 have very highly homologous genomes $^{27,28}$. Nonetheless, the two strains significantly differ in the proportion of their cell envelope components ${ }^{5}$ and display distinct behavior during infection ${ }^{1}$. We reasoned that these functional differences may be also reflected in their proteomes during the cell infection cycle.

Data acquisition was initiated with an LC-MS survey scan of all the samples. Peptides that were detected in at least 5 of 6 replicates were retained for further analysis. Peptide intensities were compared over time within each strain, and across strains at each time point. Peptides that were significantly differentially expressed by 2 -fold or more in any one comparison $(\mathrm{p}=0.05)$ were assembled into an inclusion list. Backup sample aliquots were then injected and analyzed in LC-MS/MS mode, to acquire the mass spectra used for peptide sequence 
identification and subsequent protein assignment. Peptides whose expression did not vary by the criteria indicated were not included in the analysis. Thus constitutively expressed proteins whose expressions did not vary during the infection timecourse were not reported.

We used the intensity values of the differentially expressed peptides from the LC-MS survey scans to perform a multidimensional scaling analysis for each Brucella strain over the four infection time points (Figure 2A, B). This analysis was used to determine the degree of similarity of the differentially expressed peptide populations at each timepoint. Two very distinct patterns emerged. At 3 hours post infection the differentially expressed peptides from the virulent 2308 strain had their greatest expression difference relative to time zero. However, as the infection progressed this difference was substantially reduced. By 44 hours post infection, the peptides differentially expressed by 2308 appeared to have reverted close to their original expression profiles (Figure 2A). In contrast, the peptides differentially expressed by the attenuated S19 strain became progressively more different from time zero as the infection progressed and did not revert (Figure 2B). These results indicated that the strains responded to the host intracellular environment in profoundly different ways.

In total, 190 Brucella proteins were identified to be differentially expressed during the infection timecourse. Ninety proteins were uniquely differentially expressed by 2308,30 proteins were uniquely differentially expressed by $\mathrm{S} 19$, and 70 proteins were differentially expressed by both strains (Figure 2C). Proteins in the latter group did not necessarily have matched expression patterns or levels of differential expression. The 190 proteins are presented in Table 1. All the peptides identified per protein, and each peptide's individual differential expression results, are listed in the supplemental data.

\section{B. abortus 2308 reduced key metabolic pathways early after infection}

To allow comparisons of the different proteins we normalized the differential expression data to the intensity observed at time zero for each protein. While at first it appeared that the virulent B. abortus 2308 induced widespread differential expression of proteins belonging to multiple metabolic pathways, closer examination of the results suggested that a relatively small number of pathways were affected. We thus grouped the differentially expressed proteins into 16 groups, each representing a metabolic objective such as transport and utilization of iron or amino acid synthesis (Figure 3). The last group in the sequence, however, is expected to be functionally heterogeneous as it contained all the proteins whose functions have not been defined. To better enable direct comparisons between strains the same groupings were used to display the results from both strains (Figure 3,4).

Early after infection, $B$. abortus 2308 downregulated the expression of proteins associated with the vast majority of the 16 functional clusters defined (Figure 3). Multiple proteins associated with central carbon metabolism were down regulated. For instance, tricarboxylic acid (TCA) cycle components, such as aconitate hydratase (BAB1_0090), 2-oxoglutarate dehydrogenase (BAB1_1923), dihydrolipoamide acetyltransferase (BAB1_1922), succinyl-CoA synthetase (BAB1_1925) and malate dehydrogenase (BAB1_1927), were all reduced at similar rates 3 hours after infection. Similarly, transketolase (BAB1_1740) and enolase (BAB1_1155), enzymes committed to the pentose phosphate shunt and the subsequent generation of pyruvate, were also reduced 3 hours after infection. Others, like components of the pyruvate dehydrogenase complex (BAB1_1149, BAB1_1150, BAB1_1151) required for the generation of Acetyl-CoA remained unchanged at this early time. Two proteins putatively involved in the galactose metabolism, galactonate dehydratase (BAB2_0294) and UDP-glucose-4-epimerase (BAB2_0694), and one galactose transporter (BAB2_0938), were also reduced within 24 hours after infection, as were other sugar metabolism enzymes and several sugar $\mathrm{ABC}$ transporters (BAB2_0377, BAB2_0938, BAB2_0547, BAB1_0238). Interestingly, the decline of the Omp2b porin (BAB1_0660) was clearly evident at 20 hours. Two proteins (BAB1_1645 and 
BAB1_1646) that are part of the phosphoenolpyruvate carbohydrate phosphotransferase system (PTS) dependent on the dihydroxyacetone kinase complex (Dha) and the putative periplasmic rhizopine-related ABC transporter RbsB (BAB1_1648) were reduced 3 hours postinfection and remained reduced throughout the infection period. Since the PTS energytransducing systems are involved in carbohydrate uptake and control of carbon metabolism, reduced functional activity may be the result of short supply of sugar substrates within the Brucella containing compartments.

In contrast, enzymes associated with amino acid catabolism were increased. Hydantoinase (BAB2_0559) expression increased greater than 10-fold early after infection. This enzyme catalyses the hydrolysis of creatinine to sarcosine, which can be metabolized to urea. Hydantoinase can also generate glutamate through the catabolism of proline, which could be transformed to $\alpha$-ketoglutarate. Moreover, enzymes like glutamate-ammonia ligase adenylyltransferase (BAB1_0638), which controls the activity of glutamine synthetase, also increased substantially early after infection. This enzyme and $\mathrm{N}$-formylglutamate amidohydrolase (BAB1_1763) which acts on carbon-nitrogen bonds can also increase the pool of glutamate necessary to generate $\alpha$-ketoglutarate required for the TCA cycle. The latter enzyme decreased early after infection, which may suggest the presence of feedback control mechanisms. Hydantoinase, and glutamate-ammonia ligase adenylyltransferase return to preinfection levels only at 44 hours after infection. This suggests that using amino acids as a carbon source may be maintained for a protracted period of time.

Proteins associated with protein and RNA synthesis were also reduced early after infection. For example, 14 of 18 ribosomal proteins differentially expressed by B. abortus 2308 , as well as their respective cofactors required for protein synthesis, were reduced 3 hours after infection. Concomitantly, the two differentially expressed proteins of the DNA-directed RNA polymerase complex RpoB (BAB1_1264) and RpoC (BAB1_1263) and the $\sigma^{70}$-factor RNA polymerase binding protein RpoD (BAB1_1498) were also similarly reduced. In addition, NusA (BAB1_2163) involved in the pausing of RNA polymerase during transcription also decreased early after infection. Since these proteins form part of enzymatic complexes that act in concert during the transcription of most housekeeping bacterial genes ${ }^{29,30}$, these results suggest further that transcription and bacterial protein synthesis appeared to be generally depressed early after infection. The vast majority of the proteins indicated, as well as the others not mentioned but displayed in Figure 3, gradually recovered their pre-infection expression levels over the remaining infection timecourse. A few proteins such as the TmrE (BAB1_2063) increased early after infection, but was reduced subsequently. Although the physiological function of this highly conserved GTPase is not known, it seems to be involved in translational regulation through tRNA modification ${ }^{31}$.

Respiration protein expression patterns appeared particularly interesting. Practically all the components involved in oxidative phosphorylation were either reduced early after infection (BAB1_1901, BAB1_1875, BAB1_1558, BAB1_1807 and BAB1_1808) or remained unaltered (BAB1_0824, BAB1_0828, BAB1_0414). While components of the NADH dehydrogenase complex-I and proteins of the cytochrome bc complex-III remained low through all the intracellular period, proteins of the ATP synthase complex-V increased close to pre-infection stages by 20 hours and 44 hours after infection. In addition, the riboflavin synthase (BAB2_0545) and the demethylubiquinone methyltransferase (BAB1_1875) required for the synthesis of cofactors for flavoproteins and ubiquinone, respectively, follow the same kinetics as the complex II proteins. None of the proteins of complex IV which mediate the final reaction of the electron transport chain that transfers electrons to oxygen, were differentially expressed. Concomitantly to these adjustments in the respiration chain, the PrrA (BAB1_0136) regulatory protein was reduced early after infection, reverted to pre-infection levels at 20 hours, and increased beyond pre-infection levels at 44 hours post infection. PrrA 
is a member of the two component regulatory system PrrA/PrrB which is involved in sensing oxygen tension changes in other alpha-proteobacteria ${ }^{32,33}$. These results strongly suggest that Brucella may switch to a low oxygen tension type of respiration early after infection.

\section{B. abortus 2308 increased transporters, iron metabolism and modified its cell envelope topology at later stages of infection}

Of the 30 known periplasmic proteins that were differentially expressed by B. abortus 2308 , 20 were reduced early in infection. This suggested that at this initial time the availability of substrates that could be incorporated by intracellular Brucella was low. Since 17 of 30 of periplasmic proteins then increased later in infection, it follows that the ER, which constitutes the Brucella replicative niche, appears able to supply at least some required substrates for bacterial growth. Among the transporters whose expression increased considerably were inner membrane and inner membrane associated energy coupled transporters (BAB2_0493, BAB2_0703, BAB2_1011), indicating active mobilization of molecules through the cell envelope. In agreement with the proteomic analysis of $B$. abortus outer membrane fragments ${ }^{5}$, only Omp2b porin isotype (BAB1_0660) was detected, confirming that the Omp2a is not differentially expressed, either in bacteriological cultures or in cells.

Of particular interest was the differential expression of proteins involved in the capture and transport of iron (Figure 3). The isochorismatase lyase enzyme EntB (BAB2_0013) putatively involved in the synthesis of the siderophore brucebactin, the $\mathrm{Fe}^{+++} \mathrm{ABC}$ transporter (BAB2_0539), the high affinity Fe ${ }^{++}$binding protein Tpd-like (BAB2_0840), the ExbB membrane proton channel (BAB1_1679), the Fe-anguibactin siderophore binding protein FatB (BAB2_0564) and the siderophore receptor heme transporter (BAB2_1150), were all reduced or remained unchanged 3 hours after infection. However, all these proteins increased at 20 and 44 hours post infection. Moreover, a significant increase in one component of the TonBdependent receptor protein (BAB2_0233), which has been implicated in the internalization of siderophores such as 2,3 $\mathrm{DHBA}^{34}$, was already observed at 3 hours post infection. These changes suggested that the active synthesis of siderophores and iron capture did not occur early after bacterial invasion but rather at later times, once the bacteria had begun replicating in the ER.

Proteins putatively involved in LPS biogenesis, such as Omp1 (BAB1_1176) and the lectinlike BA14 (BAB2_0505) were reduced early but approached pre-infection levels at 20 and 44 hours post infection, while others like the Pmg (BAB1_0055), which supplies sugar substrates for the $\mathrm{O}$ chain polysaccharide synthesis ${ }^{35}$, increased early and remained elevated throughout the infection period. It has been proposed that Omp1 is involved in the translocation of LPS to the outer membrane ${ }^{36}$, while deletion of BA14 generates rough attenuated mutants ${ }^{37}$. The BA14 protein has been shown to be augmented in the BvrR/BvrS two component regulatory system attenuated mutants ${ }^{5}$, stressing the relevance of this Omp protein during Brucella intracellular survival. Similarly pmg deficient mutants generate attenuated rough type LPS mutants ${ }^{35}$. These protein profiles suggested that the synthesis of the $\mathrm{O}$ chain was initiated shortly after bacterial invasion while translocation of LPS to the outer membrane occurred later in the intracellular infection.

It is noteworthy that the amounts of putative enzymes such as the 3-oxoacyl-(acyl-carrierprotein) synthase II FabF (BAB1_0486), the inner membrane proteins 3-hydroxydecanoylACP dehydratase FabA (BAB1_2174), Acetyl-CoA carboxylase (BAB1_0925) and 3ketoacyl-acyl-carrier reductase FabG (BAB1_0483), as well as the glutaryl-CoA dehydrogenase GcdH (BAB1_1109), involved in the synthesis of fatty acids for membrane lipids, were all reduced early after infection, suggesting that Acetyl-CoA may be in short supply at the beginning of the infection. While some of these enzymes remained low (BAB1_1109, BAB2_0975, BAB1_0925), the others reverted at later times to pre-infection levels. In 
addition, the levels of glycerol-3-phosphate dehydrogenase (BAB2_0371), which is involved in the synthesis of glycerophospholipids was also reduced early after infection, but increased to pre-infection levels 44 hours after infection, once the bacteria were within their replicating niche.

Striking changes in the differential expression of Omps were observed through the infection timecourse. For instance, the major OmpA (BAB1_1226) was reduced early after infection but then increased to pre-infection levels at 20 and 44 hours, once Brucella has reached the ER. In contrast, the Omp16 lipoprotein (BAB1_1707) practically remained unchanged at 3 and 20 hours post infection, and was considerably reduced at 44 hours. The most abrupt changes were observed for Omp160 (BAB1_0046), Omp90 (BAB1_0942) and the TonB-dependent receptor protein (BAB2_0233). The functions of the former two proteins have not been determined, but deletion of the Omp160 generates attenuated Brucella 38. The Omp expression changes indicate adjustments to the outer membrane topology, which were very probably physiological adaptations to the various intracellular environments. Moreover, the non-synchronized changes to the cell envelope proteins suggest that the Brucella cell envelope composition may be in continual flux throughout the infection timecourse.

\section{B. abortus 2308 prepares for cell division soon after infection}

A critical step of Brucella parasitism is intracellular replication, which generally becomes evident after approximately 8 hours of infection ${ }^{12}$. Several proteins involved in Brucella division and DNA metabolism, however, were overexpressed earlier in infection. The histidine kinase membrane sensor protein PleC (BAB1_0640) and the exodeoxyribonuclease XseA (BAB2_0475) both became overexpressed early and dropped to pre-infection levels at 44 hours. While the former protein may act as a phosphatase of the division protein DivK, leading to its accumulation in the pole of the cell ${ }^{39}$, the latter seems to be devoted to the repair of DNA mismatches. Two proteins involved in DNA relaxation, the TldD peptidase (BAB1_0490) and the ABC UvrB (BAB1_1530) were also overexpressed early after infection, and dropped to pre-infection levels afterwards. Furthermore, expression of a negative regulator of septum formation, MinD (BAB2_0883) 39,40 $^{39}$ was reduced early in infection and remained low throughout the intracellular lifecycle, whereas another protein, MepA (BAB2_1008), putatively proposed to be involved in peptidoglycan degradation, a function required for septum formation, was similarly reduced early after infection but increased to pre-infection levels later. It seems likely that the pathogen, even while not actively dividing early after infection, appeared to be preparing to initiate replication once all the necessary transcription and protein synthesis functions resumed.

\section{Regulatory protein expression in intracellular B. abortus 2308}

As reflected by the proteomic changes, Brucella undergoes extensive metabolic adjustments during the pathogen's transition from bacteriological media to the host cell's environment. Bacterial regulatory systems would be key elements to successfully adjust its physiology to the new conditions. A number of differentially expressed proteins that were part of metabolic processes described earlier, also fulfill regulatory roles: the $\sigma^{70}$-factor RNA polymerase binding protein $\mathrm{RpoD}$, the $\mathrm{PleC}$ involved in the control of intracellular bacteria replication, the NusA that allows the RNA polymerase to pause at specific sites in the nascent transcript for the regulation of gene expression, and the PrrA DNA binding protein of a system involved in the regulation of bacterial respiration type.

A key bacterial regulator is the Bvr two-component system, composed of the sensor protein $\mathrm{BvrS}$ and the regulatory protein $\mathrm{BvrR}^{41}$. The BvrR/BvrS two-component system exerts strong influence over the homeostasis and structure of the Brucella cell envelope, mainly Omp group 3 proteins, lipoproteins, LPS, several periplasmic transporters, and stress response 
components $5,42,43$. The Bvr system is crucial for virulence. Mutations in either the sensor or the regulatory protein generate attenuated mutants with defects in attachment, invasion, and intracellular replication. Significant differential expression of BvrR (BAB1_2092) was observed. However, contrary to expectation, BvrR protein expression was reduced 3 hours post infection, remained at low levels at 20 hours but reverted to pre-infection levels at 44 hours post-infection. Whereas the presence of the Bvr two-component system appears essential for the initiation of an intracellular infection, these results suggest that during the infection's early stages the Bvr system may be shut off. Later at 44 hours, however, BvrR reverted to preinfection levels and may have resumed its direct regulatory role as the bacteria prepared to exit the infected host cells.

\section{Protein expression changes in intracellular B. abortus S19}

Approximately $60 \%$ fewer proteins were differentially expressed by S19 during the infection timecourse compared to 2308 . There were also 3 times fewer proteins uniquely differentially expressed by S19 compared to 2308 (Figure 4). It therefore appears that the adaptive response by the attenuated strain to the intracellular environment is not as versatile and extensive as that of the virulent strain. Moreover, the overall S19-specific protein expression patterns differed from those displayed by 2308 . Whereas in 2308 the drop in protein expression early in infection was mostly followed by a gradual reversion to pre-infection levels later in the infection, in S19 most of the proteins differentially expressed either continued to increase or to decrease as the infection progressed. There were substantially fewer proteins differentially expressed by S19 in key processes such as carbon metabolism, respiration, amino acid synthesis, protein synthesis, as well as iron metabolism, compared to 2308 . However, a similar number of proteins were differentially expressed by both strains in transcription, stress response, transport, and outer membrane topology. This may indicate that the differences between the two strains may be traceable to a relatively limited number of differentially expressed proteins.

To further investigate the physiological differences between B. abortus S19 and 2308, we compared the expression patterns of proteins identified to be differentially expressed by both strains. The expression patterns for each of these proteins were compared and their Pearson correlation score was determined (Figure 5A). A correlation score of 1 indicated that a protein's expression patterns in both strains matched perfectly, whereas a score of 0.5 indicated that they did not. A score of -1 indicated expression patterns that were mirror image opposites. We established a score of 0.75 as the minimum threshold for a good correlation. Only 21 of 71 commonly differentially expressed proteins, approximately $30 \%$ of the total, met that correlation threshold. The majority of the proteins differentially expressed by both strains, therefore, did not have matching expression patterns. To determine when during the infection timecourse the expression patterns diverged, we compared each protein's expression in both strains at each infection timepoint. To enable direct comparisons across strains, we normalized the expression data to the virulent 2308 strain at time 0, and derived S19 to 2308 protein expression ratios for each time point (Figure 5B). At 3 hours post infection most of the commonly differentially expressed proteins had ratios of approximately 1 (Figure 5B). Only 17 of 71 proteins $(24 \%)$ had ratios significantly different than 1 . The great majority of these, 13 proteins, were preferentially overexpressed by S19. Later in the infection the number of proteins preferentially overexpressed by S19 fell slightly to 8 proteins at the 20-hour time point and 7 proteins at 44 hours. Thus, of the proteins that were differentially expressed by both strains a relatively small proportion was preferentially overexpressed by S19 throughout most of the timecourse. In contrast, the proteins preferentially overexpressed by 2308 changed substantially. Only 4 of the 71 commonly differentially expressed proteins had ratios significantly below 1 at 3 hours post infection. That number tripled to 12 at 20 hours post infection, and doubled again to 24 at 44 hours post infection. This data indicated that early in infection the commonly differentially expressed proteins had comparable expression profiles 
in both strains. However, as the infection progressed, 2308 appeared to outpace S19 in production of many of these proteins, resulting in divergent expression patterns.

\section{Verification of proteomic results}

Western blot analysis was used to confirm the differential expression of BvrR in preparations of intracellular bacteria at different times of infection (Figure 6A). Western blots, however, have low sensitivity and resolution in comparison to mass spectrometry and are limited by reagent availability as well. Thus to verify the differential expression of additional proteins, we developed multiple reaction monitoring (MRM) methods for an additional 19 differentially expressed proteins. MRM is an established clinical chemistry tool for the quantitation of small molecules $^{21,22}$. In the past few years this method has been adapted to the quantitation of proteins in complex biological samples ${ }^{23,24}$. We acquired the peptide transition data using backup samples prepared for the initial proteomics analysis. The MRM results confirmed the initial differential expression patterns observed. A subset of the results is displayed in Figure 6. Additional results can be found in the supplemental data. The MRM analyses along with the limited Western blot data verified the accuracy of the proteomics results.

\section{Discussion}

Although the intracellular trafficking of Brucella in macrophages is broadly known, we have a limited understanding of the molecular mechanisms utilized by these pathogenic bacteria. In this study we observed that the virulent intracellular Brucella executed a coordinated series of protein changes commensurate with metabolic adjustments predicted to reflect the intravacuolar environmental conditions at each stage of infection. One early key adjustment was to reduce proteins involved in the central carbon utilization. Reduced expression was observed in enzymes involved in the TCA, pyruvate and pentose phosphate shunt cycles, as well as in the uptake and transport of sugar substrates. This is relevant because, at least in bacteriological cultures, the pentose phosphate shunt seems to be the main pathway Brucella uses to derive energy from available sugars and for carbon metabolism ${ }^{44,45}$. Indeed, phosphofructokinase, an essential enzyme for glycolysis, is absent in Brucella 28 and the Entner-Doudoroff pathway seems non-functional, at least in B. abortus 44,45 . It should be noted, however, that enzymes involved in the catabolism of proteins and amino acids increased mainly early after infection, suggesting that amino acid-based alternatives ${ }^{46}$ may be the preferred solution for Brucella to derive precursors, such as glutamate, for generating TCA cycle substrates in early and midpoint infection. Later, once the bacteria have reached the ER, the pentose phosphate shunt seems to partially resume its functions. These metabolic adjustments may be a reflection of the substrates available to the bacteria during the different stages of the infection. This interpretation is supported by the uniform reduction of 5 sugar transporters (BAB2_0377, BAB2_0938, BAB2_0547, BAB1_0238, BAB1_0660) during this period, suggesting a limited availability of sugar substrates throughout the intracellular infection period. Alternative routes that bypass some steps of the TCA cycle, such as the glyoxylate shunt, may be used as optional pathways. However, the corresponding enzymes isocitrate lyase and the malate synthase, of the glyoxylate shunt were not detected as differentially expressed.

A number of the coordinated expression changes occurred in proteins that form continuous genetic arrangements. For example BAB1_1922, BAB1_1923, BAB1_1925, as well as BAB1_1149, BAB1_1150, BAB1_1151, and BAB1_1645, BAB1_1646, BAB1_1648. These proteins may be transcribed as a single message and subsequently translated as has been observed in other systems ${ }^{47}$. The latter trio of genes defines a putative phosphoenolpyruvate carbohydrate phosphotransferase system (PTS; BAB1_1645 and BAB1_1646) and a predicted periplasmic rhizopine-related ABC transporter RbsB (BAB1_1648). These 3 proteins form 
part of a genetic arrangement composed of seven contiguous open reading frames highly conserved in several alpha-proteobacteria. Although it is not known if the genetic arrangement in Brucella corresponds to the PTS operon working in other proteobacteria ${ }^{47}$, it is worth noting that the Brucella genetic configuration coding for the putative dihydroxyacetone enzymes and the corresponding regulatory protein suggests that these genes may also act in concert in this bacterium. As stated previously, the bacterial Dha kinases are a family of related enzymes which utilize the PTS as a source of high-energy phosphate ${ }^{47}$. This PTS energy-transducing system, involved in carbohydrate uptake and control of carbon metabolism, is ubiquitous in eubacteria. The specific function of these PTS systems in alpha-proteobacteria is unknown, and many of their members, including Brucella, lack the corresponding sugar permeases to incorporate hexoses ${ }^{48}$. However, the differential expression of DhaK (BAB1_1645 and BAB1_1646) and the corresponding rhizopine RbsB transporter (BAB1_1648), strongly suggest that this system is fully functional in Brucella. It is also worth noting that the two component regulatory protein BvrR (BAB1_2092) which is part of a system transcribed together with enzymes of another PTS system (unpublished results, and X. De Bolle personal communication) was lowered early in infection and returned to pre-infection levels after the bacteria initiated replication. We therefore conclude that during the reduced sugar substrate availability in the intracellular milieu, these particular PTS systems which depend on the incorporation of sugars may be reduced in favor of other alternatives for control of carbon metabolism.

In addition to low substrate availability, it is likely that intracellular Brucella may also have to confront low oxygen tension ${ }^{49}$. Under such conditions the pathogen has to adapt to alternative respiration options ${ }^{50}$. The reduction of the flavoprotein complex II SdhA protein (BAB1_1901) early in infection, as well as the reduction of two critical proteins of complex I (NuoC, BAB1_0824 and NuoG, BAB1_0828) and the complex-III protein PetB (BAB1_1558) suggested that $B$. abortus 2308 assumed low oxygen tension respiration functions early in infection. Alternatively, in the absence of oxygen, Brucella may be forced to use formate dehydrogenase and D-lactate dehydrogenase for electron transfer as well as reduction of nitrate to nitrogen ${ }^{50}$. However, differential expression in different terminal oxidoreductases was not detected. Despite a significant increase of proteins involved in iron uptake observed at later times of infection, the use of $\mathrm{Fe}^{+++}$as a terminal electron acceptor is precluded because Brucella lacks the ferric iron reductase gene that encodes the final acceptor enzyme system. The increase or reversion to pre-infection levels of several ATP synthase complex-V proteins later in infection is consistent with the hypothesis of a late stage increase in substrate availability as articulated above.

Respiration appears to be highly regulated in alpha-proteobacteria ${ }^{33}$. PrrA is a global transcription regulator activated upon phosphorylation by its cognate kinase PrrB in response to changes in oxygen conditions ${ }^{32}$. PrrA coordinately controls a large number of genes involved in the complex switch between aerobic and anaerobic lifestyles and the optimum use of reducing power. Indeed, it has been observed that the PrrA/PrrB system regulates genes necessary for the synthesis of the photosynthetic apparatus, electron transport, nitrogen and carbon fixation, anaerobic respiration, hydrogenase and aerotaxis, as well as the expression of the Prr gene cluster itself ${ }^{32,33}$. Therefore, it is likely that the PrrA differential expression detected in intracellular Brucella is related to the adaptation of the bacteria to low oxygen tension conditions within phagosomes.

Most of the differentially expressed enzymes involved in the biosynthesis of amino acids were reduced 3 hours after infection, but had reverted or increased beyond pre-infection levels 44 hours after infection. Similarly, differentially expressed enzymes involved in the purine and pyrimidine biosynthesis were considerably reduced early in infection before reverting to preinfection levels. As indicated above, an important exception was hydantoinase 
(BAB2_0559), which increased early in infection and is predicted to be involved in amino acid catabolism. These results strongly suggest that early after infection, intracellular Brucella lowers its transcriptional and translational synthetic metabolism. The relevance of reinstalling amino acid, protein and RNA synthesis at the time of bacterial replication is illustrated by the fact that mutations in the genes coding for 3 proteins differentially expressed devoted to amino acid metabolism (BAB2_0515, BAB1_1399, BAB1_1397), 2 dedicated to protein synthesis (BAB1_0025, BAB1_0917), one belonging to the RNA polymerase complex (BAB1_1264), and the trigger factor Tig (BAB1_0917), which is the first protein to interact with nascent polypeptides emerging from the ribosome, generate attenuated Brucella phenotypes ${ }^{51-55}$. There was also an early augmentation of the tRNA modification GTPase TrmE. This highly conserved protein is involved in the modification of uridine bases (U34) at the first anticodon (wobble) position of tRNAs decoding two-family box triplets, and therefore can influence translation $^{31}$. In 2308, but not in S19, TrmE expression was subsequently lower at 20 hours and 44 hours after infection, suggesting that in the virulent strain translational homeostasis may have reached equilibrium once the bacterium has established its replicating niche.

GroEL (BAB2_0189) and ribosome recycling factor Frr (BAB1_1181) have been reported to increase under heat shock and remain unchanged during low $\mathrm{pH}$ or oxidative stress ${ }^{8}$. Both proteins were observed to considerably diminish 3 hours after infection, increasing to preinfection levels later. The iron-binding Tpd-like protein (BAB2_0840) and pyruvate dehydrogenase AceF (BAB1_1150) reported to lower during heat shock and remain unchanged during oxidative or low $\mathrm{pH}$ stress 8 , become increased later in intracellular infection. SodC (BAB2_0535), reported to increase during oxidative stress but remained unchanged after heat or acidic $\mathrm{pH}$, was reduced 3 hours after infection before reverting to pre-infection levels later. Other proteins such as malate dehydrogenase (BAB1_1927), ribosomal protein SSU S1 (BAB1_0025), Bfr (BAB2_0675) ABC transporter (BAB1_0238) and BvrR (BAB1_2092), reported to be reduced in at least one of the stringent conditions ${ }^{8}$, were also observed to be reduced early in infection. These results confirm and expand previous claims suggesting that the stringent response profile observed in intracellular bacteria does not match that of Brucella growth in media under defined stress conditions ${ }^{7}$. However, it might be possible to use the metabolic changes observed in this work to formulate media and growth conditions, for example that use certain amino acids as the only carbon sources as well as low oxygen tension, to more precisely mimic the intracellular microenvironment.

The later increase of proteins devoted to iron metabolism is striking. At the stationary phase, heme seems to be a major iron source in Brucella and the BhuA protein (BAB2_1150) has been proposed to be the main heme transporter ${ }^{56}$. It has been demonstrated that the bhuA gene is only expressed under iron deprivation and the B. abortus bhuA deletion mutant exhibits significant attenuation as it is unable to maintain chronic infections in mice ${ }^{56}$. This suggests that at later stages, Brucella adapts to a stationary phase type of metabolism, which may be generated not only by the low availability of substrates, but by crowd effect triggered by quorum sensing molecules ${ }^{57}$.

\section{Conclusions}

We can therefore propose the following model: After phagocytosis, virulent Brucella reaches early phagosomes and initiates subversion of intracellular trafficking. Three hours after infection, most of the intracellular Brucella organisms are still alive within transitional compartments that have not fused with lysosomes or ER derived vacuoles ${ }^{11}$. This transitional compartment does not seem to confront Brucella with particularly stressful conditions, such as oxygen radicals or other microbicidals. This early environment is consistent with the low levels of bacterial oxidative response proteins, chaperones and other important stress response molecules that remain low at this time. Within this compartment, however, Brucella has to 
confront moderate acidic conditions ${ }^{49}$, as revealed by the low levels of some bacterial proteins such as the malate dehydrogenase, which decreases during low $\mathrm{pH}$ stress ${ }^{8}$.

At this early time of infection, the intracellular bacterium initiates its adaptation to low oxygen tension type of respiration, responding to the conditions of intracellular compartments.

Reduced availability of extracellular substrates in the phagosome also promotes the decrease of periplasmic transporters and the reduction of central carbon metabolic pathways, such as the TCA cycle, which appears to operate at a restricted level. The bacterium switches to anaplerotic routes, and generation of glutamate by enzymatic conversion of amino acids, for making the necessary intermediates for the reduced output TCA cycle. At this critical time, the bacterium activates several catabolic pathways to generate essential substrates by using its own macromolecules, mainly ribosomes or abundant stress response proteins. The bacterium also restricts its protein and nucleic acid synthesis, and down regulates the two component BvrR/ $\mathrm{BvrS}$ regulatory system essential for the biogenesis of the outer membrane and periplasmic space. In contrast, other regulatory systems devoted to the control of cell division and DNA repair mechanisms are activated. The bacterium appears to be preparing for the next replicating phase. Thanks to its non-canonical pathogen-associated molecular patterns, which are weak macrophage activators, Brucella has stealthily survived for three hours without significantly activating the killing mechanisms of the host cell ${ }^{7}$. At this point the type IV secretion system $\mathrm{VirB}^{58}$ and the apoptosis inhibitory mechanisms for maintaining the host cell alive are obvious ${ }^{59}$.

Three hours after infection the fate of intracellular Brucella is marked by one of two different outcomes. Vacuoles containing bacteria that have avoided lysosomal fusion begin to associate with compartments of the ER by means of LPS, cyclic glucans and mediators released by the type IV secretion system ${ }^{11,60-63}$. Bacteria in vacuoles that successfully fuse with ER proceed to replicate within this compartment ${ }^{10,11}$. Vacuoles containing bacteria that did not avoid lysosomal fusion, however, will present harsh conditions to the intracellular bacteria which will eventually be destroyed within phagolysosomes ${ }^{4,11}$. It is thus expected that the declining bacteria within lysosomal compartments would display a different proteome profile from those that successfully achieved fusions with the ER and have survived.

Twenty hours after infection, Brucella metabolism has fully adapted to a low oxygen tension type of respiration, by means of the PrrA/PrrB two component regulatory system, while continuing to use amino acids as a carbon source. Transporters involved in the capture of amino acids and peptides have increased, reflecting the availability of these substrates within the ER. Protein and nucleic acid synthesis have resumed. Chaperone and antioxidant protein expression has increased to support protein synthesis by providing protein folding and damage protection functions. Capture and transportation of iron, essential in many metabolic processes, has increased. The topology of the outer membrane has changed again to reflect this new environment. At this point the infected macrophages still do not display signs of activation ${ }^{59}$, despite the fact that they are not refractory to be activated by external influences ${ }^{4}$.

After almost two days of intracellular life, Brucella has achieved extensive replication within the infected cells ${ }^{1}$. Many of the differentially expressed proteins have reverted to pre-infection expression levels. Forty four hours after infection, all the regulatory systems that increased or decreased earlier in infection have approached pre-infection levels, while others like those devoted to iron uptake remain high, suggesting that the bacterial physiology may be entering a stationary phase type of homeostasis ${ }^{64,65}$.

It is striking that transcriptomic profiling of Brucella infected RAW macrophages, revealed that the most conspicuous changes of infected host cells also occurred early in infection ${ }^{59}$. It seems that as the infection advances the metabolic functions of both the pathogen and host cell 
tend to approach basal levels. The reasons for this parallel biological behavior between parasite and its host cell is not known, but it is tempting to speculate that after the early critical crosstalk that decides the fate of both type of cells, they may establish a more symmetrical relationship that could be the basis Brucella parasitism and long lasting infections.

A small proportion of $B$. abortus S19 appear capable of replicating inside macrophages ${ }^{14,15}$. It is not known if the bacteria evade host defenses using the same strategies as virulent $B$. abortus. However, the few B. abortus S19 that avoid lysosomal digestion appear to replicate within the ER as virulent bacteria do ${ }^{13}$. The reduction in metabolic and biosynthetic activity seen in the virulent strain also appears to occur in the attenuated strain, but to a far lesser extent which may affect the persistence of the attenuated strain inside cells. Similarly the apparent shift to low oxygen tension type of respiration early in infection seems to be less extensive in the attenuated strain. Later in infection, when the virulent strain re-establishes protein and nucleic acid synthesis, the attenuated strain appears unable to match that level of adjustment. Moreover, it does not seem to upregulate iron metabolism nor modify its cell envelope composition to the same extent as the virulent strain. Perhaps the attenuated strain's inability to sufficiently adjust its metabolism early in infection compromises its capacity to fully exploit the ER microenvironment in mid and late infection. This also suggests that effective antimicrobial strategies for combating virulent $B$. abortus infections could be developed by limiting the bacterium's ability to catabolize amino acids or switch to low oxygen tension type of respiration early in infection. Furthermore, given that these two metabolic adjustments are made to adapt to the phagosome microenvironment, strategies to inhibit them may have utility on other bacterial species that use phagosome subversion to establish intracellular infections.

\section{Supplementary Material}

Refer to Web version on PubMed Central for supplementary material.

\section{Acknowledgments}

This work was funded by the NIAID/NIH contract HHSN266200400056C. Additional funding was from CONAREFondo del Sistema (FS), Costa Rica. We thank Ignacio Moriyón from University of Navarra, Spain for his advice on carbon metabolism and Roy Martin Roop II, Department of Microbiology and Immunology East Carolina University School of Medicine for his advice on iron metabolism.

\section{References}

1. Moreno, E.; Moriyón, I. The Genus Brucella. In: Dworkin, M.; Falkow, S.; Rosenberg, E.; Schleifer, KH.; Stackebrant, E., editors. The Prokaryotes. Vol. 5. Springer-Verlag; New York: 2006. p. 315-456.

2. Moreno E, Stackebrandt E, Dorsch M, Wolters J, Busch M, Mayer H. Brucella abortus 16S rRNA and Lipid A Reveal A Phylogenetic Relationship With Members Of The Alpha-2 Subdivision Of The Class Proteobacteria. J Bacteriol 1990;172:3569-3576. [PubMed: 2113907]

3. Moreno E, Moriyón I. Brucella melitensis: A Nasty Bug with Hidden Credentials for Virulence. Proc Nat Acad Sci USA 2002;99:1-3. [PubMed: 11782541]

4. Barquero-Calvo E, Chaves-Olarte E, Weiss DS, Guzmán-Verri C, Chacón-Díaz C, Rucavado A, Morrión I, Moreno E. Brucella abortus Uses a Stealthy Strategy to Avoid Activation of the Innate Immune System During the Onset of Infection. PLoS One 2007;2:e631.10.1371/journal.pone.0000631 [PubMed: 17637846][Online]

5. Lamontagne J, Butler H, Chaves-Olarte E, Hunter J, Schirm M, Paquet C, Tian M, Kearney P, Hamaidi L, Chelsky D, Moriyón I, Moreno E, Paramithiotis E. Extensive Cell Envelope Modulation is Associated with Virulence in Brucella abortus. J Proteom Res 2007;6:1519-1529.

6. Eskra L, Canavessi A, Carey M, Splitter G. Brucella abortus Genes Identified Following Constitutive Growth and Macrophage Infection. Infect Immun 2001;69:7736-7742. [PubMed: 11705955] 
7. Rafie-Kolpin M, Essenberg RC, Wyckoff JH. $3^{\text {rd }}$. Identification and Comparison of MacrophageInduced Proteins and Proteins Induced Under Various Stress Conditions in Brucella abortus. Infect Immun 1996;64:5274-5283. [PubMed: 8945577]

8. Teixeira-Gomes AP, Cloeckaert A, Zygmunt MS. Characterization of Heat, Oxidative, and Acid Stress Responses in Brucella melitensis. Infect Immun 2000;68:2954-2961. [PubMed: 10768994]

9. Nicoletti, P. Vaccination. In: Nielsen, K.; Duncan, JR., editors. Animal Brucellosis. CRC Press; Boca Raton: 1990. p. 284-299.

10. Pizarro-Cerdá J, Meresse S, Parton RG, van der Goot G, Sola-Landa A, Lopez-goni I, Moreno E, Gorvel JP. Brucella abortus Transits Through the Autophagic Pathway and Replicates in the Endoplasmic Reticulum of Nonprofessional Phagocytes. Infect Immun 1998;66:5711-5724. [PubMed: 9826346]

11. Celli J, de Chastellier C, Pizarro-Cerdá J, Moreno E, Gorvel JP. Brucella Evasion of Macrophage Killing Through VirB-Dependent Sustained Interactions with the Endoplasmic Reticulum. J Exp Med 2003;198:545-556. [PubMed: 12925673]

12. Moreno, E.; Gorvel, JP. Invasion, Intracellular Trafficking and Replication of Brucella Organisms in Professional and Non-Professional Phagocytes. In: López-Goñi, I.; Moriyón, I., editors. Brucella: Molecular and Cellular Biology. Horizon Scientific Press; United Kingdom: 2004. p. 287-312.

13. Pizarro-Cerdá J, Desjardins M, Moreno E, Akira S, Gorvel JP. Modulation of Endocytosis in Nuclear Factor IL-6(-/-) Macrophages is Responsible for a High Susceptibility to Intracellular Bacterial Infection. J Immunol 1999;162:3519-3526. [PubMed: 10092809]

14. Jones SM, Winter A. Survival of Virulent and Attenuated Strains of Brucella abortus in Normal and Gamma Interferon-Activated Murine Peritoneal Macrophages. Infect Immun 1992;60:3011-3014. [PubMed: 1612769]

15. Jiang X, Baldwin CL. Effects of Cytokines on Intracellular Growth of Brucella abortus. Infect Immun 1993;61:124-134. [PubMed: 8418034]

16. Monreal D, Grilló MJ, González D, Marín CM, De Miguel MJ, López-Goñi I, Blasco JM, Cloeckaert A, Moriyón I. Characterization of Brucella abortus O-polysaccharide and Core Lipopolysaccharide Mutants and Demonstration that a Complete Core is Required for Rough Vaccines to be Efficient Against Brucella abortus and Brucella ovis in the Mouse Model. Infect Immun 2003;71:3261-71. [PubMed: 12761107]

17. Kovach ME, Elzer PH, Hill DS, Robertson GT, Farris MA, Roop RM II, Peterson KM. Four New Derivatives of the Broad-Host-Range Cloning Vector pBBR1MCS, Carrying Different AntibioticResistance Cassettes. Gene 1995;166:175-176. [PubMed: 8529885]

18. Chaves-Olarte E, Guzmán-Verri C, Méresse S, Desjardins M, Pizarro-Cerdá J, Badilla J, Gorvel JP, Moreno E. Activation of Rho and Rab GTPases Dissociates Brucella abortus Internalization from Intracellular Trafficking. Cell Microbiol 2002;4:663-676. [PubMed: 12366403]

19. Benjamini Y, Hochberg Y. Controlling the False Discovery Rate: A Practical and Powerful Approach to Multiple Testing. J Royal Stat Soc Ser B 1995;57:289-300.

20. Lekpor K, Benoit MJ, Butler H, Schirm M, Vasilescu D, Bonter K, Chelsky D, Hugo P, Hunter J, Opiteck G, Paramithiotis E, Kearney P. An Evaluation of Multidimensional Fingerprinting in the Context of Clinical Proteomics. Proteomics Clin Appl 2007;1:456-466.

21. Lee MS, Kerns EH. LC/MS Applications in Drug Development. Mass Spectrom Rev 1999;18:187279. [PubMed: 10568041]

22. Desiderio D, Kai M. Preparation of Stable Isotope Incorporated Peptide Internal Standards for Field Desorption Mass Spectrometry Quantification of Peptides in Biologic Tissue. Biomed Mass Spectrom 1983;3:43-46.

23. Gerber SA, Rush J, Stemman O, Kirschner MW, Gygi SP. Absolute Quantification of Proteins and Phosphoproteins from Cell Lysates by Tandem MS. Proc Natl Acad Sci USA 2003;100:6940-6945. [PubMed: 12771378]

24. Keshishian H, Addona T, Burgess M, Kuhn E, Carr SA. Quantitative, Multiplexed Assays for Low Abundance Proteins in Plasma by Targeted Mass Spectrometry and Stable Isotope Dilution. Mol \& Cell Proteomics 2007;6:2212-2229.

25. Weiss DS, Takeda K, Akira S, Zychlinsky A, Moreno E. MyD88, but not TLR4 and TLR2, is Required for Efficient Clearance of Brucella abortus. Infect Immun 2005;73:5137-5143. [PubMed: 16041030] 
26. Pizarro-Cerdá J, Desjardins M, Moreno E, Akira S, Gorvel JP. Modulation of endocytosis in nuclear factor IL-6(-/-) macrophages is responsible for a high susceptibility to intracellular bacterial infection. J Immunol 1999;162:3519-3526. [PubMed: 10092809]

27. Crasta OR, Folkerts O, Fei Z, Mane SP, Evans C, Martino-Catt S, Bricker B, Yu G, Du L, Sobral BW. Genome Sequence of Brucella abortus Vaccine Strain S19 Compared to Virulent Strains Yields Candidate Virulence Genes. PLoS ONE 2008;3:e2193. [PubMed: 18478107]

28. Halling SM, Peterson-Burch BD, Bricker BJ, Zuerner RL, Qing Z, Li LL, Kapur V, Alt DP, Olsen SC. Completion of the Genome Sequence of Brucella abortus and Comparison to the Highly Similar Genomes of Brucella melitensis. Brucella suis J Bacteriol 2005;187:2715-2726.

29. Gruber TM, Gross CA. Multiple Sigma Subunits and the Partitioning of Bacterial Transcription Space. Annu Rev Microbiol 2003;57:441-466. [PubMed: 14527287]

30. Yakhnin AV, Babitzke P. NusA-Stimulated RNA Polymerase Pausing and Termination Participates in the Bacillus subtilis trp Operon Attenuation Mechanism In Vitro. Proc. Natl. Acad. Sci. U. S. A 2002;99:11067-11072.

31. Scrima A, Vetter IR, Armengod ME, Wittinghofer A. The Structure of the TrmE GTP-Binding Protein and its Implications for tRNA Modification. EMBO J 2005;24:23-33. [PubMed: 15616586]

32. Laguri C, Stenzel RA, Donohue TJ, Phillips-Jones MK, Williamson MP. Activation of the Global Gene Regulator PrrA (RegA) from Rhodobacter sphaeroides. Biochemistry 2006;45:7872-7881. [PubMed: 16784239]

33. Emmerich R, Hennecke H, Fischer HM. Evidence for a Functional Similarity Between the TwoComponent Regulatory Systems RegSR, ActSR, and RegBA (PrrBA) in Alpha-Proteobacteria. Arch Microbiol 2000;174:307-313. [PubMed: 11131020]

34. Roop, RM., 2nd; Bellaire, BH.; Anderson, E.; Paulley, JT. Iron Metabolism in Brucella. In: LópezGoñi, I.; Moriyón, I., editors. Brucella: Molecular and Cellular Biology. Horizon Scientific Press; United Kingdom: 2004. p. 243-262.

35. Ugalde JE, Czibener C, Feldman MF, Ugalde RA. Identification and Characterization of the Brucella abortus Phosphoglucomutase Gene: Role of Lipopolysaccharide in Virulence and Intracellular Multiplication. Infect Immun 2000;68:5716-5723. [PubMed: 10992476]

36. Iriarte, M.; Gonzélez, D.; Delrue, RM.; Montreal, D.; Conde, R.; Lopez-Goñi, I.; Letesson, JJ.; Moriyón, I. Brucella Lipopolysaccharide: Structure, Biosynthesis and Genetics. In: López-Goñi, I.; Moriyón, I., editors. Brucella: Molecular and Cellular Biology. Horizon Scientific Press; United Kingdom: 2004. p. 159-191.

37. Vemulapalli TH, Vemulapalli R, Schurig GG, Boyle SM, Sriranganathan N. Role in virulence of a Brucella abortus protein exhibiting lectin-like activity. Infect Immun 2006;74:183-191. [PubMed: 16368972]

38. Wu Q, Pei J, Turse C, Ficht TA. Mariner mutagenesis of Brucella melitensis reveals genes with previously uncharacterized roles in virulence and survival. BMC Microbiol 2006;6:102-116. [PubMed: 17176467]

39. Hallez R, Mignolet J, Van Mullem V, Wery M, Vandenhaute J, Letesson JJ, Jacobs-Wagner C, De Bolle X. The Asymmetric Distribution of the Essential Histidine Kinase PdhS Indicates a Differentiation Event in Brucella abortus. EMBO J 2007;26:1444-1455. [PubMed: 17304218]

40. Hallez R, Letesson JJ, Vandenhaute J, De Bolle X. Gateway-Based Destination Vectors for Functional Analyses of Bacterial ORFeomes: Application to the Min System in Brucella abortus. Appl Environ Microbiol 2007;73:1375-1379. [PubMed: 17172460]

41. Lopez-Goni I, Guzman-Verri C, Manterola L, Sola-Landa A, Moriyon I, Moreno E. Regulation of Brucella Virulence by the Two-Component System BvrR/BvrS. Vet Microbiol 2002;90:329-339. [PubMed: 12414153]

42. Guzmán-Verri C, Manterola L, Sola-Landa A, Parra A, Cloeckaert A, Garin J, Gorvel JP, Moriyón I, Moreno E, López-Goñi I. The Two-Component System BvrR/BvrS Essential for Brucella abortus Virulence Regulates the Expression of Outer Membrane Proteins with Counterparts in Members of the Rhizobiaceae. Proc Natl Acad Sci USA 2002;99:12375-12380. [PubMed: 12218183]

43. Manterola L, Guzmán-Verri C, Chaves-Olarte E, Barquero-Calvo E, de Miguel MJ, Moriyón I, Grilló MJ, López-Goñi I, Moreno E. BvrR/BvrS-Controlled Outer Membrane Proteins Omp3a and Omp3b 
are Not Essential for Brucella abortus Virulence. Infect Immun 2007;75:4867-4874. [PubMed: 17664262]

44. Essenberg RC, Seshadri R, Nelson K, Paulsen I. Sugar Metabolism by Brucellae. Vet Microbiol 2002;90:249-261. [PubMed: 12414147]

45. Robertson DC, McCullough WG. The Glucose Catabolism of the Genus Brucella. I. Evaluation of Pathways. Arch Biochem Biophys 1968;127:263-273. [PubMed: 4972340]

46. Dunn MF. Tricarboxylic Acid Cycle and Anaplerotic Enzymes in Rhizobia. FEMS Microbiol Rev 1998;22:105-123. [PubMed: 9729766]

47. Bachler C, Schneider P, Bahler P, Lustig A, Erni B. Escherichia coli Dihydroxyacetone Kinase Controls Gene Expression by Binding to Transcription Factor DhaR. EMBO J 2005;24:283-293. [PubMed: 15616579]

48. Letesson, JJ.; De Bolle, X. Brucella Virulence: a Mater of Control. In: López-Goñi, I.; Moriyón, I., editors. Brucella: Molecular and Cellular Biology. Horizon Scientific Press; United Kingdom: 2004. p. 117-158.

49. Jubier-Maurin, V.; Loisel, S.; Liautard, JP.; Köhler, S. The Intramacrophagic Environment of Brucella spp. and Their Replicative Niche. In: López-Goñi, I.; Moriyón, I., editors. Brucella: Molecular and Cellular Biology. Horizon Scientific Press; United Kingdom: 2004. p. 313-340.

50. DelVecchio VG, Kapatral V, Redkar RJ, Patra G, Mujer C, Los T, Ivanova N, Anderson I, Bhattacharyya A, Lykidis A, Reznik G, Jablonski L, Larsen N, D’Souza M, Bernal A, Mazur M, Goltsman E, Selkov E, Elzer PH, Hagius S, O’Callaghan D, Letesson JJ, Haselkorn R, Kyrpides N, Overbeek R. The Genome Sequence of the Facultative Intracellular Pathogen Brucella melitensis. Proc Natl Acad Sci USA 2002;99:443-448. [PubMed: 11756688]

51. Ficht TA. Intracellular Survival of Brucella: Defining the Link with Persistence. Vet Microbiol 2003;92:213-223. [PubMed: 12523983]

52. Lestrate P, Dricot A, Delrue RM, Lambert C, Martinelli V, De Bolle X, Letesson JJ, Tibor A. Attenuated Signature-Tagged Mutagenesis Mutants of Brucella melitensis Identified During the Acute Phase of Infection in Mice. Infect Immun 2003;71:7053-7060. [PubMed: 14638795]

53. Delrue RM, Lestrate P, Tibor A, Letesson JJ, De Bolle X. Brucella Pathogenesis, Genes Identified From Random Large-Scale Screens. FEMS Microbiol Lett 2004;231:1-12. [PubMed: 14979322]

54. Foulongne V, Bourg G, Cazevieille C, Michaux-Charachon S, O'Callaghan D. Identification of Brucella suis Genes Affecting Intracellular Survival in an In Vitro Human Macrophage Infection Model by Signature-Tagged Transposon Mutagenesis. Infect Immun 2000;68:1297-1303. [PubMed: 10678941]

55. Marianelli C, Ciuchini F, Tarantino M, Pasquali P, Adone R. Genetic Bases of the Rifampin Resistance Phenotype in Brucella spp. J Clin Microbiol 2004;42:5439-5443. [PubMed: 15583262]

56. Paulley JT, Anderson ES, Roop RM. $2^{\text {nd }}$. Brucella abortus Requires the Heme Transporter BhuA for Maintenance of Chronic Infection in BALB/c Mice. Infect Immun 2007;75:5248-5254. [PubMed: 17709407]

57. Taminiau B, Daykin M, Swift S, Boschiroli ML, Tibor A, Lestrate P, De Bolle X, O'Callaghan D, Williams P, Letesson JJ. Identification of a quorum-sensing signal molecule in the facultative intracellular pathogen Brucella melitensis. Infect Immun 2002;70:3004-3011. [PubMed: 12010991]

58. Boschiroli ML, Ouahrani-Bettache S, Foulongne V, Michaux-Charachon S, Bourg G, AllardetServent A, Cazevieille C, Liautard JP, Ramuz M, O'Callaghan D. The Brucella suis virB Operon is Induced Intracellularly in Macrophages. Proc Natl Acad Sci US A 2002;99:1544-1549.

59. He Y, Reichow S, Ramamoorthy S, Ding X, Lathigra R, Craig JC, Sobral BW, Schurig GG, Sriranganathan N, Boyle SM. Brucella melitensis Triggers Time-Dependent Modulation of Apoptosis and Down-Regulation of Mitochondrion-Associated Gene Expression in Mouse Macrophages. Infect Immun 2006;74:5035-5046. [PubMed: 16926395]

60. Arellano-Reynoso B, Lapaque N, Salcedo S, Briones G, Ciocchini AE, Ugalde R, Moreno E, Moriyón I, Gorvel JP. The Cyclic b-1,2-glucan is a Brucella Virulence Factor Required for Intracellular Survival. Nature Immunol 2005;6:618-625. [PubMed: 15880113]

61. den Hartigh AB, Rolán HG, de Jong MF, Tsolis RM. VirB3 to VirB6 and VirB8 to VirB11, but not VirB7, are Essential for Mediating Persistence of Brucella in the Reticuloendothelial System. J Bacteriol 2008;190:4427-4436. [PubMed: 18469100] 
62. Detilleux PG, Deyoe BL, Cheville NF. Penetration and Intracellular Growth of Brucella abortus in Nonphagocytic Cells In Vitro. Infect Immun 1990;158:2320-2328. [PubMed: 2114362]

63. de Jong MF, Sun YH, den Hartigh AB, van Dijl JM, Tsolis RM. Identification of VceA and VceC, Two Members of the VjbR Regulon That Are Translocated Into Macrophages by the Brucella Type IV Secretion System. Mol Microbiol. 2008 Oct 24;[Epub ahead of print]

64. Roop RM 2nd, Gee JM, Robertson GT, Richardson JM, Ng WL, Winkler ME. Brucella StationaryPhase Gene Expression and Virulence. Annu Rev Microbiol 2003;57:57-76. [PubMed: 12730323]

65. Anderson ES, Paulley JT, Roop RM 2nd. The AraC-Like Transcriptional Regulator DhbR is Required for Maximum Expression of the 2,3-Dihydroxybenzoic Acid Biosynthesis Genes in Brucella abortus 2308 in Response to Iron Deprivation. J Bacteriol 2008;190:1838-1842. [PubMed: 18156262] 
A
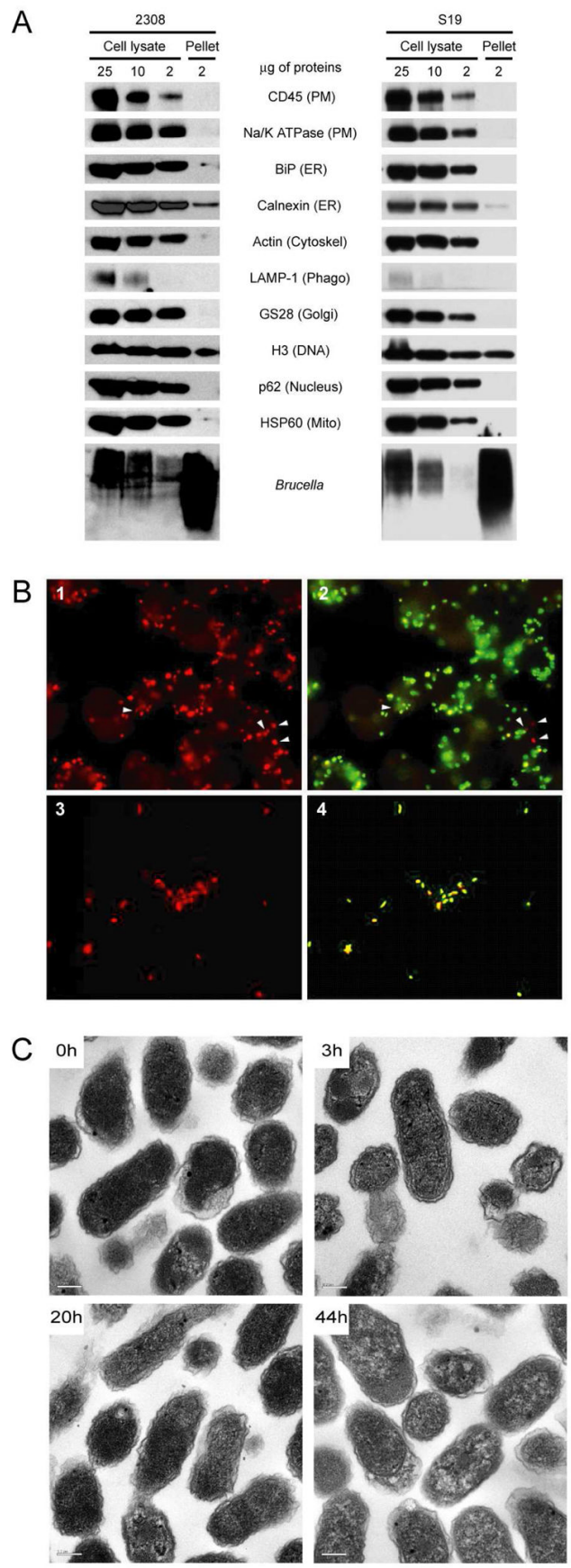

Figure 1. Isolation of intracellular Brucella

(A) Western blot analysis of infected macrophage cell lysates used for intracellular Brucella isolation, and of the intracellular Brucella final products (pellet). The starting cell lysate titration shown was used to estimate the enrichment of the final product. A representative isolation $20 \mathrm{hrs}$ after infection is shown for both bacterial strains (2308 and S19) used. (B) Immunofluorescence analysis of LPS staining (red) on GFP-expressing B. abortus 2308 inside infected macrophages (B1, B2) and following isolation (B3, B4). Bacteria that displayed both green and red fluorescence were considered viable. Bacteria that displayed only red fluorescence were considered non-viable (arrow). Representative staining $3 \mathrm{hrs}$ after infection is shown. Magnification is $40 X(B 1, B 2)$ and $100 X(B 3, B 4)$. (C) Transmission electron 
microscopy of isolated intracellular bacteria at each experimental timepoint. Magnification displayed is $43,000 \mathrm{X}$. A size bar of $0.2 \mu \mathrm{m}$ is indicated. 

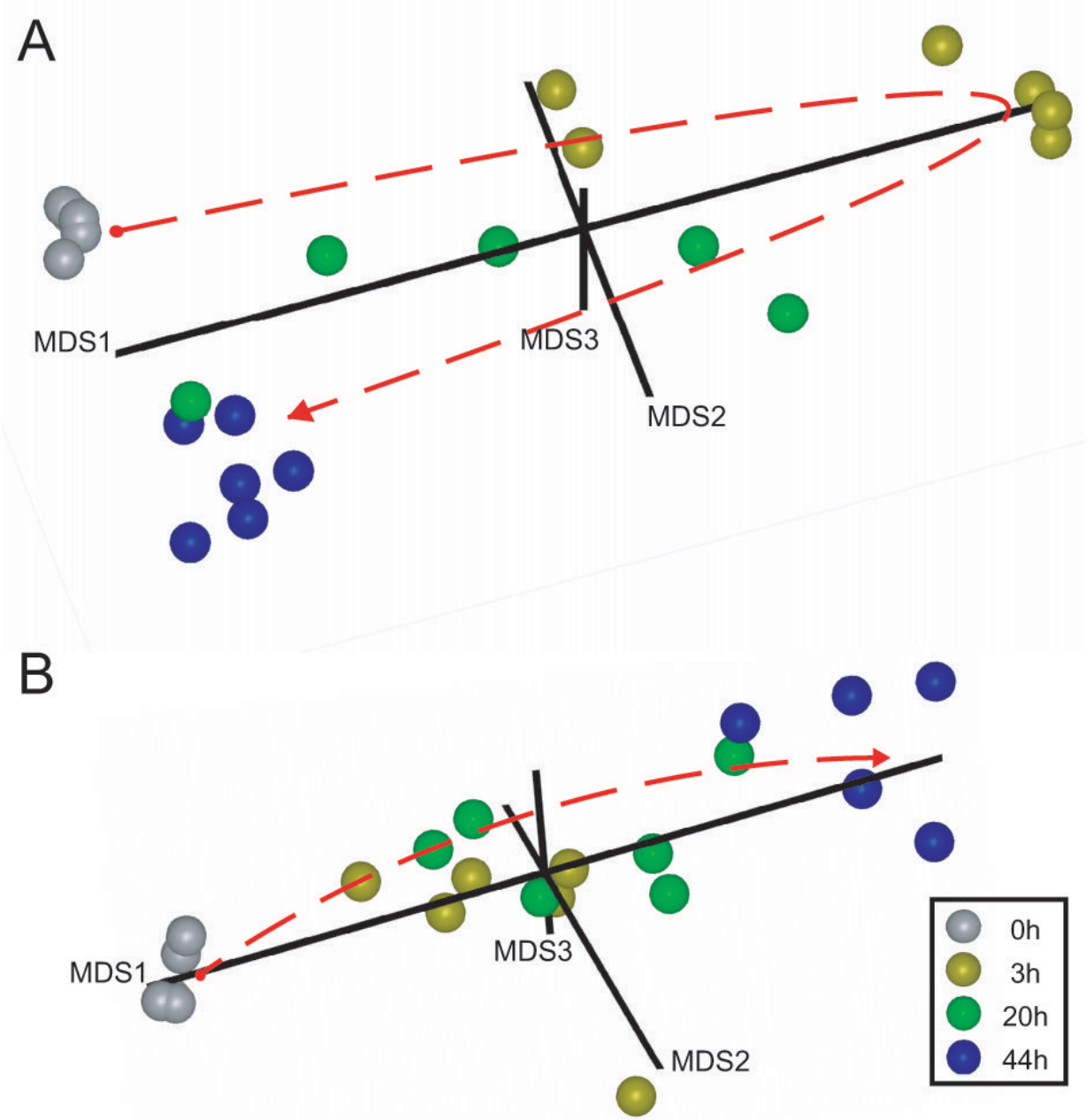

C

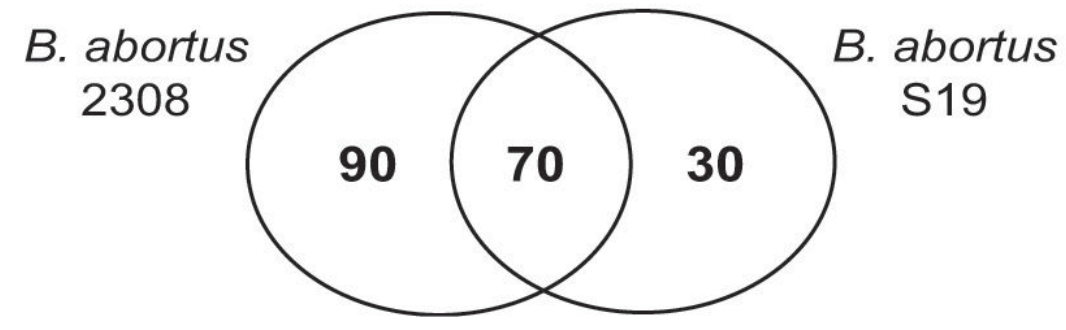

Figure 2. Global differential expression proteome analysis

Multi-dimensional scaling plot of peptides differentially expressed by B. abortus 2308 (A) and B. abortus S19 (B). Each sphere represents one independent replicate, color coded per timepoint. (C) Venn diagram illustrating the distribution of the differentially expressed proteins identified in the two strains. 

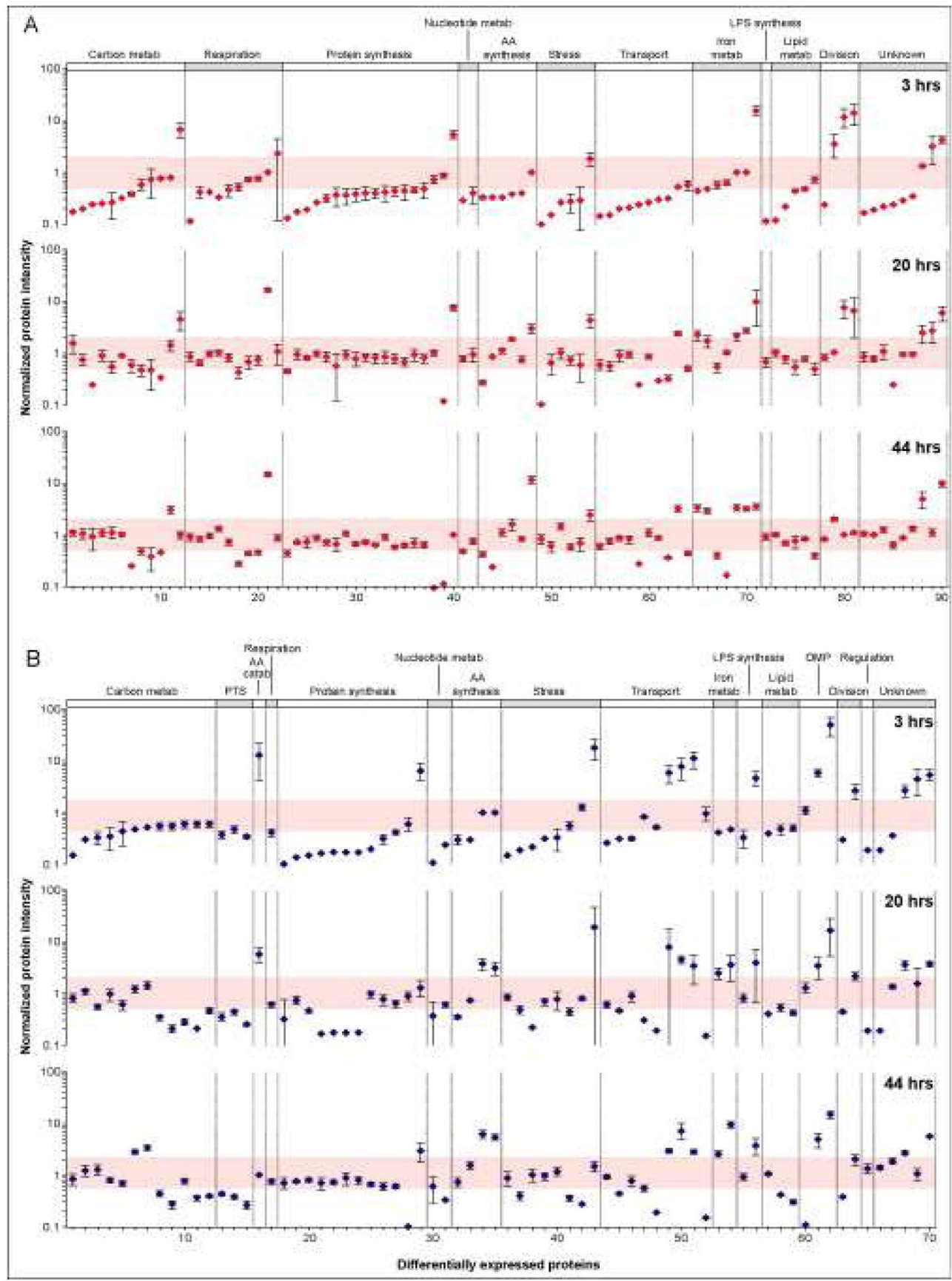

Figure 3. Proteins differentially expressed by B. abortus 2308 during an intracellular infection Intensity values per protein were normalized to time zero and displayed in logarithmic scale per timepoint (y-axis). Protein enumeration follows the numbering indicated in Table 1 ( $\mathrm{x}$ axis). The intensity values outside the colored band centered at normalized intensity 1 are considered to be differentially expressed. Median and standard deviations of 6 independent replicates are shown. (A) Proteins that were differentially expressed only by B. abortus 2308 . (B) Proteins that were differentially expressed by B. abortus 2308 and S19. The differential intensities for B. abortus 2308 are shown. 
A
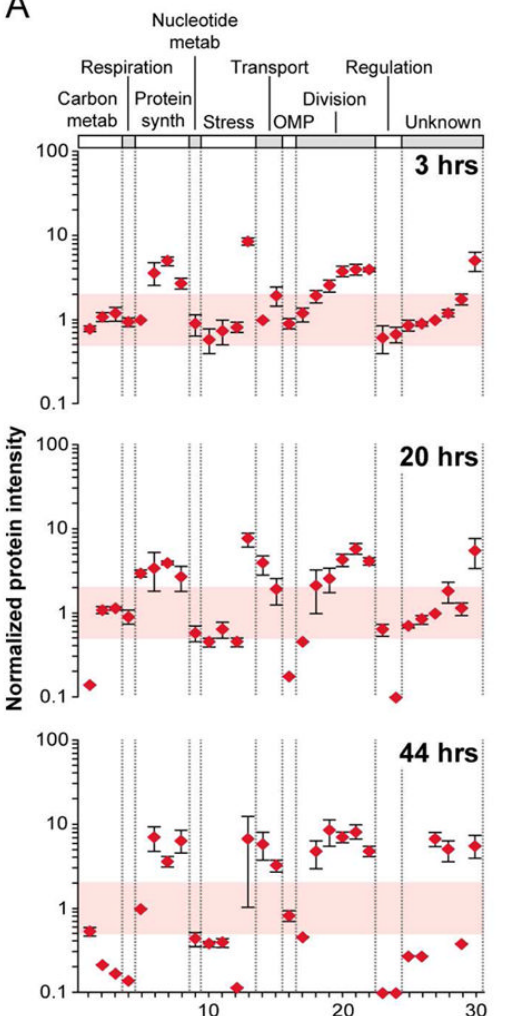

B
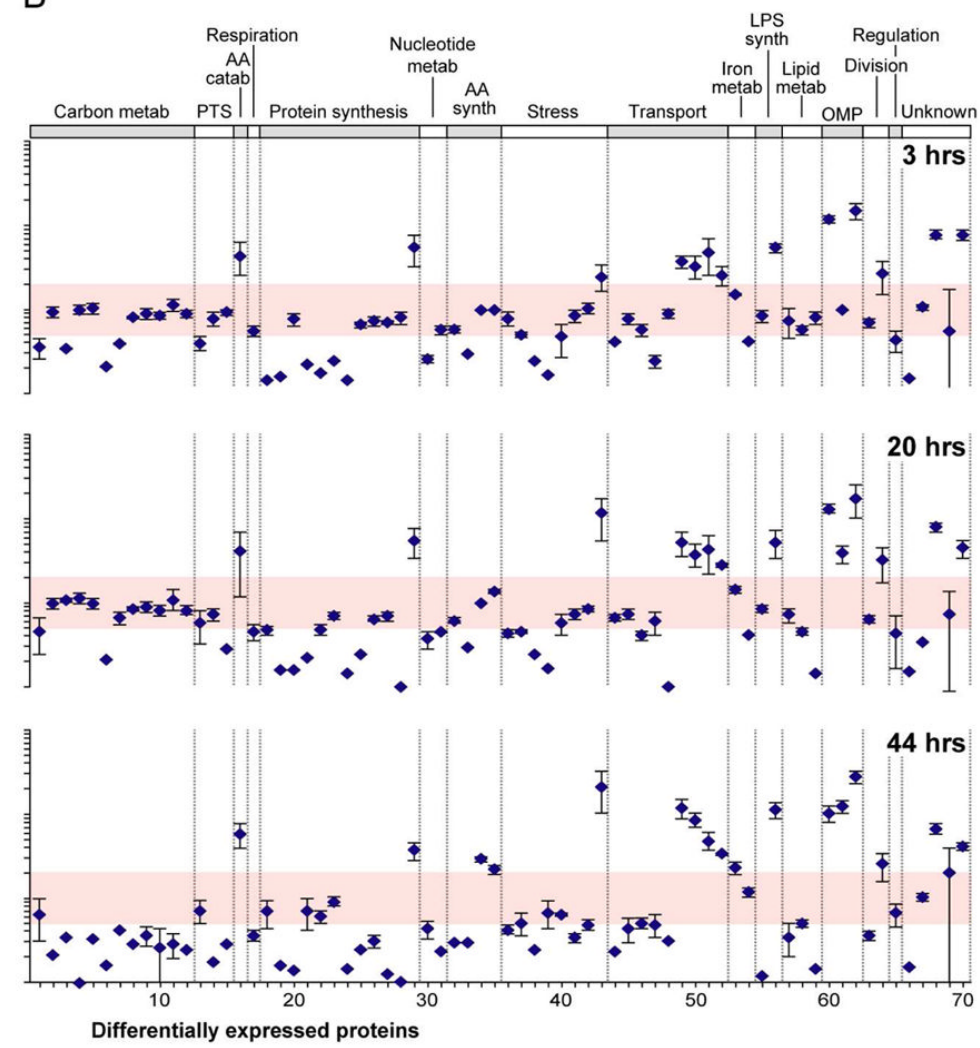

Figure 4. Proteins differentially expressed by B. abortus $\mathbf{S 1 9}$ during an intracellular infection Intensity values per protein were normalized to time zero and displayed in logarithmic scale per timepoint (y-axis). Protein enumeration follows the numbering indicated in Table 1 ( $\mathrm{x}$ axis). The intensity values outside the colored band centered at normalized intensity 1 are considered to be differentially expressed. Median and standard deviations of 6 independent replicates are shown. (A) Proteins that were differentially expressed only by B. abortus S19. (B) Proteins that were differentially expressed by B. abortus 2308 and S19. The differential intensities for B. abortus S19 are shown. 
A

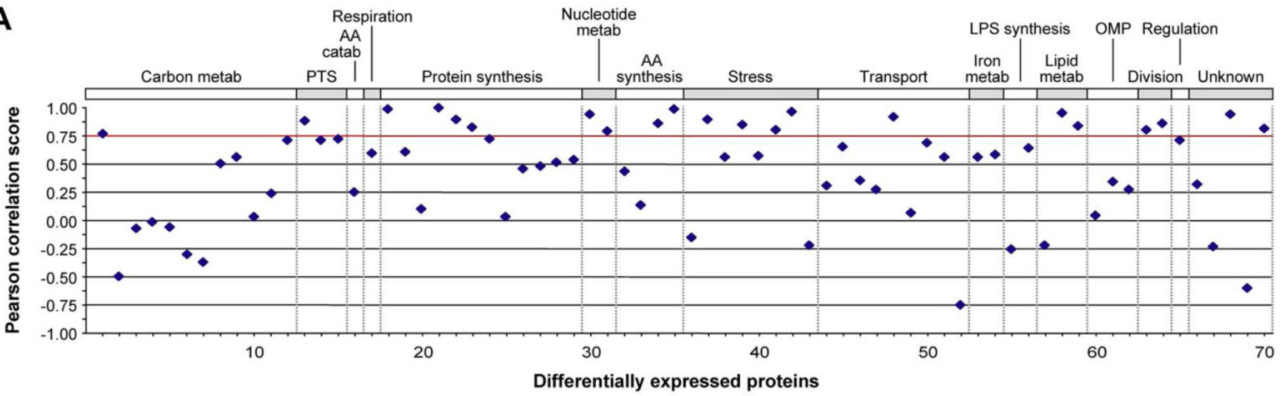

B
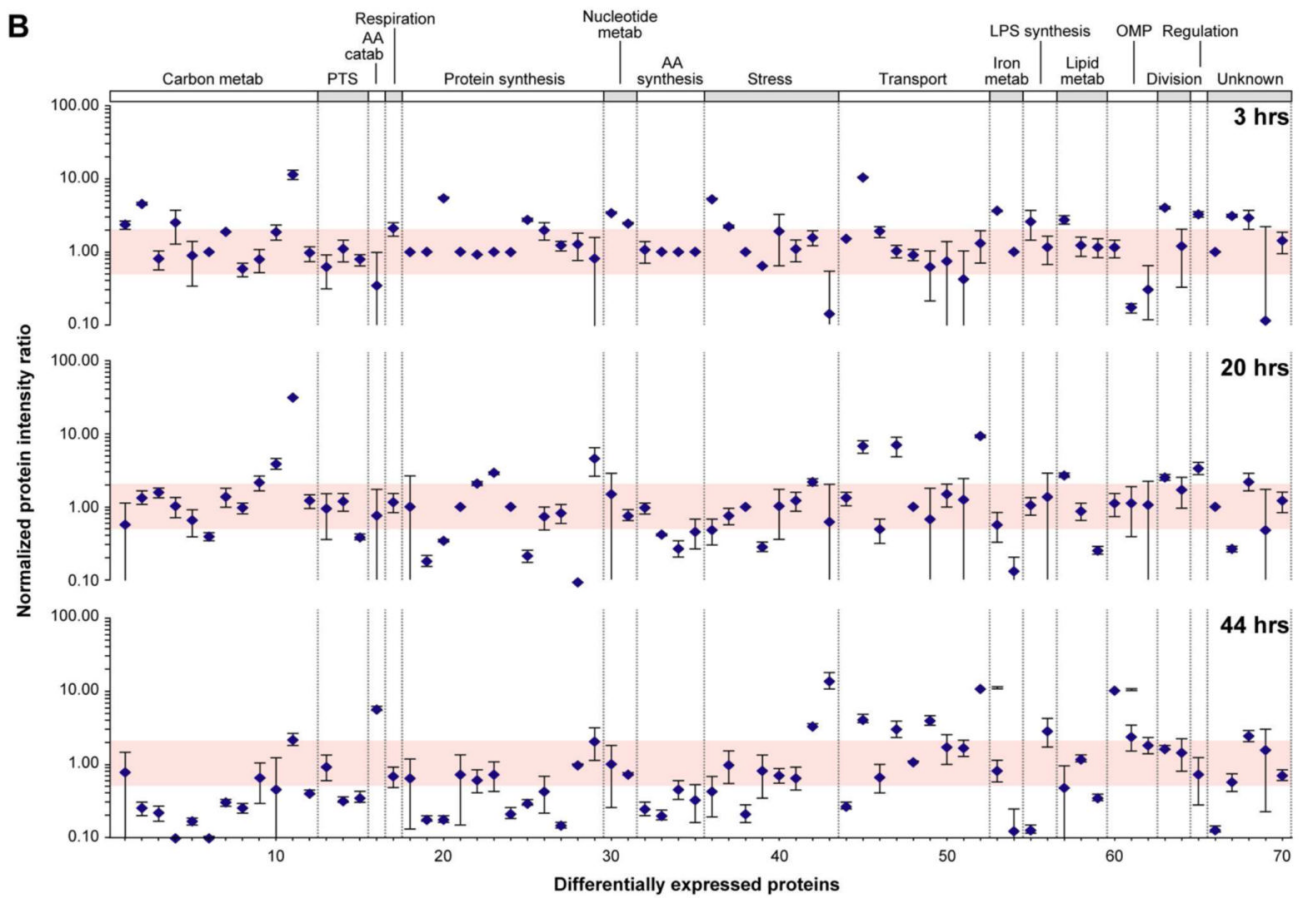

Figure 5. Comparison of proteins differentially expressed by both B. abortus 2308 and S19 during an intracellular infection

(A) Shown are the Pearson correlation values for each commonly differentially expressed protein's expression patterns in both strains (y-axis). Protein enumeration follows the numbering indicated in Table 1 (x-axis). The red line indicates a Pearson correlation value of 0.75. (B) Protein intensities were normalized to the values at time zero for the virulent 2308 strain (y-axis). Protein enumeration follows the numbering indicated in Table 1 ( $\mathrm{x}$-axis) . Proteins with values within the colored band centered at normalized intensity ratio of 1 are considered to be equivalently expressed in both strains. Median and standard deviations of 6 independent replicates are shown. 
A
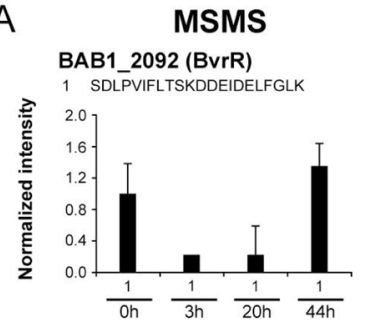

B
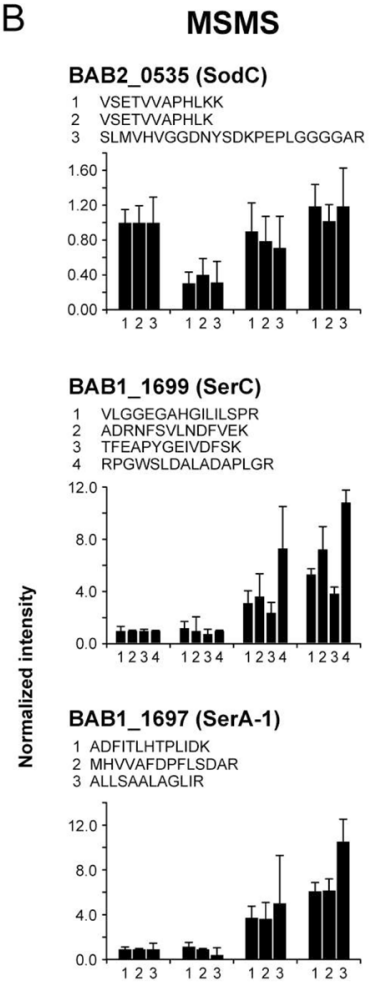

BAB2_0539 (FbpA)

1 IDTVPLSEIVSHRK
2 SSTGITVNTVEK

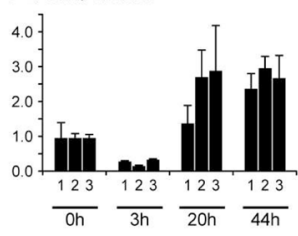

Western blot

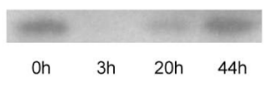

MRM
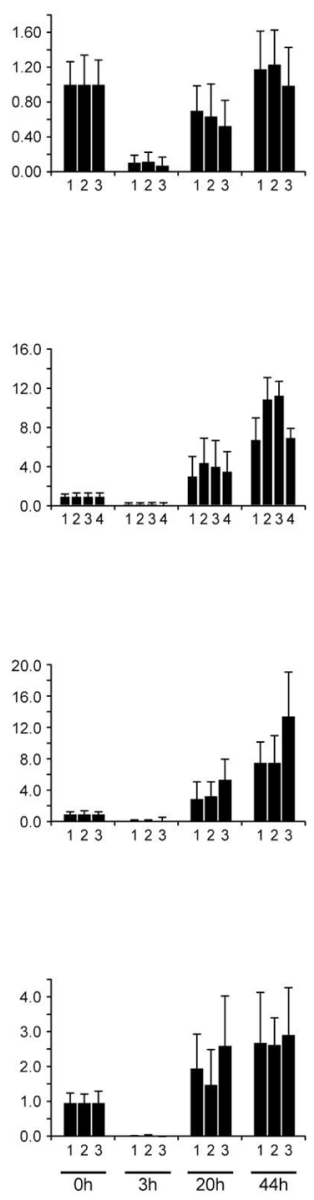

Figure 6. Verification of proteomics results

(A) Bar graph of BvrR peptide intensities measured in B. abortus 2308 were normalized to time zero and compared to western blots of isolated intracellular B. abortus 2308 homogenates. (B) Bar graph of peptide intensities of 4 proteins measured in B. abortus 2308 were normalized to time zero for each protein and compared to MRM results of the same peptides. Median and standard deviations of 6 independent replicates are shown for both the proteomics discovery and the MRM results. 


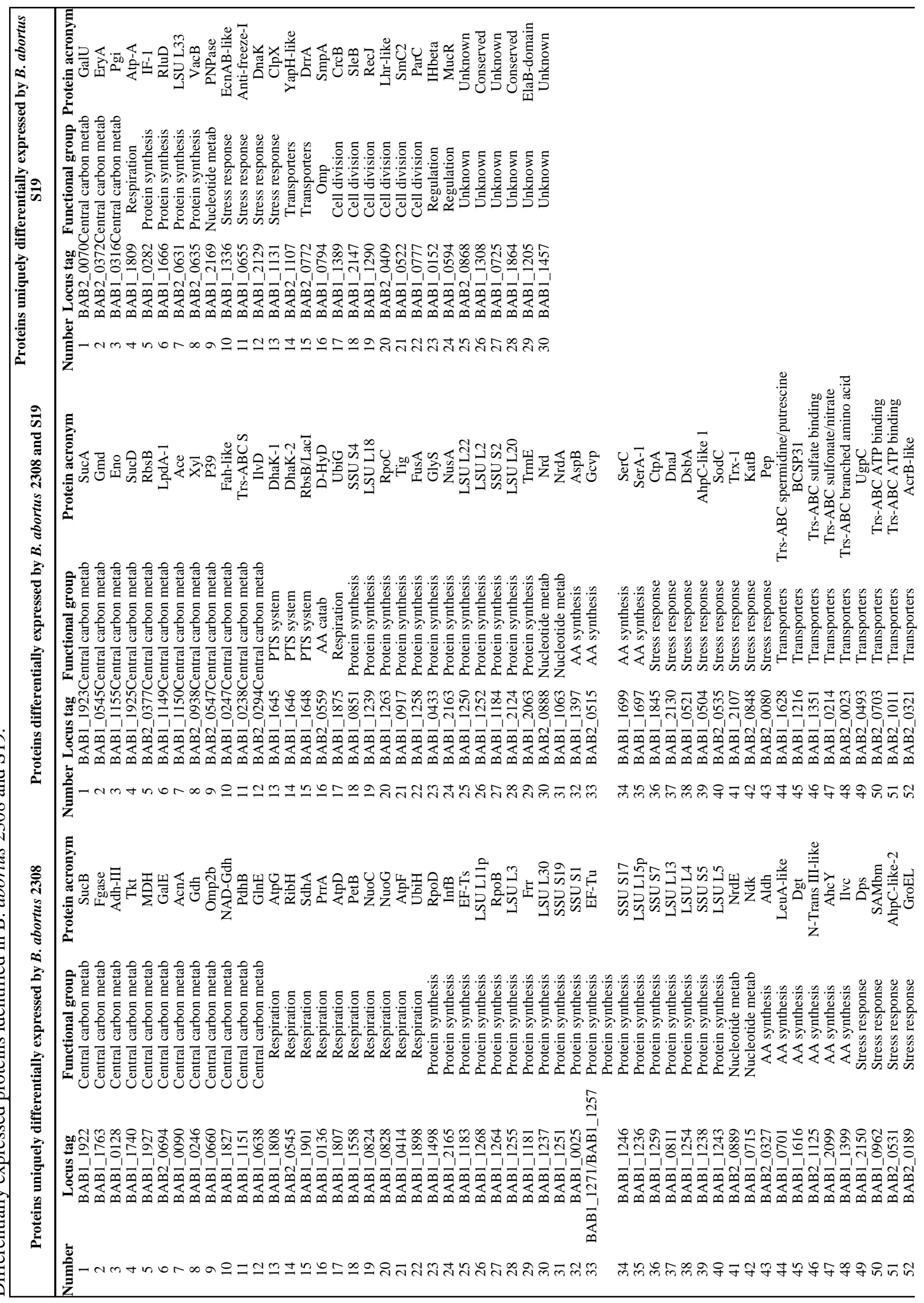

J Proteome Res. Author manuscript; available in PMC 2010 March 6. 


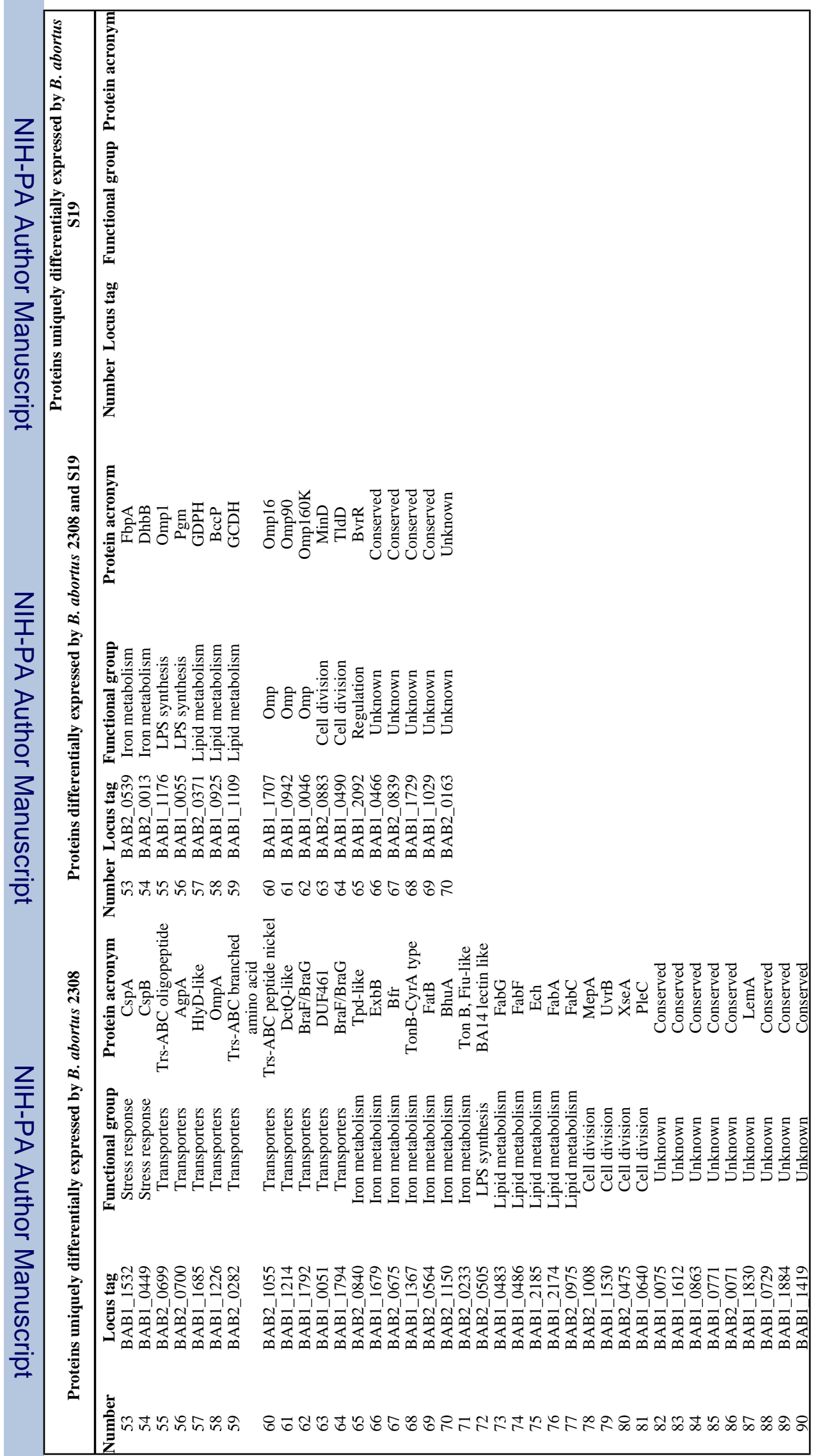

J Proteome Res. Author manuscript; available in PMC 2010 March 6. 